\title{
Primary Headache in Children and Adolescents: Update on Pharmacotherapy of Migraine and Tension-Type Headache
}

\author{
Michaela Bonfert ${ }^{1}$ Andreas Straube ${ }^{2}$ Andreas Sebastian Schroeder ${ }^{1}$ Peter Reilich $^{3}$ \\ Friedrich Ebinger ${ }^{4,5} \quad$ Florian Heinen ${ }^{1}$
}

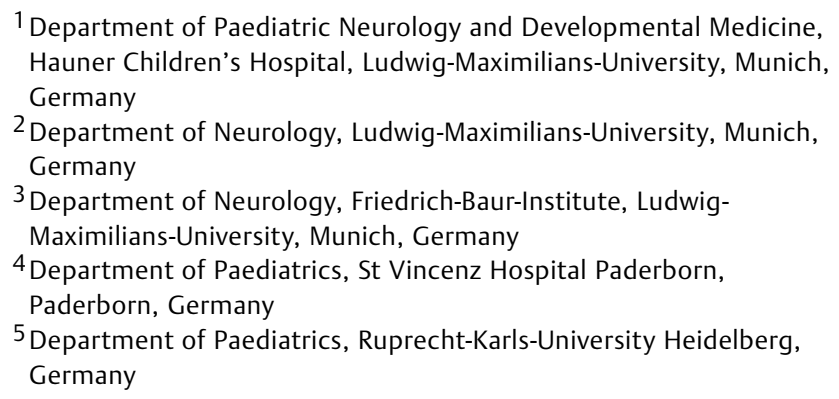

Address for correspondence and reprint requests Dr. Michaela Bonfert, MD, Department of Paediatric Neurology and Developmental Medicine, Hauner Children's Hospital, Ludwig-Maximilians-University, Munich, Germany (e-mail: michaela.bonfert@med.uni-muenchen.de).

Neuropediatrics 2013;44:3-19.

\begin{abstract}
Keywords

- migraine

- tension-type headache

- acute headache treatment

- preventive headache treatment

- prophylactic headache treatment

- pediatrics

Primary headache disorders are frequently encountered in the pediatric population. The therapeutic approach consists of a multimodal program, including lifestyle modification, psychotherapeutic intervention, pharmacotherapy, and complementary measures. This systematic review focuses on the pharmacotherapy of pediatric migraine and tension-type headache (TTH). In addition to the general treatment principles, the results of 33 clinical reports published on the topic since 2008 are outlined in detail. Furthermore, a tabular summary of previously investigated agents not studied since 2008 is given, as is an overview of promising pharmacologic approaches so far only evaluated in adults. A variety of pharmacologic options is available, but high-quality evidence is limited to single agents. At this time, approval is restricted to four triptans and flupirtine for the symptomatic treatment of pediatric acute migraine and TTH, respectively. No agent has been approved for the prevention of pediatric primary headaches. This review does not grade the drugs hierarchically because the complex profiles of many agents differ only slightly or even overlap. However, a detailed expert opinion is provided. On the basis of the outlined facts, the team of physician, patient, and parents has to decide on the most appropriate regimen for the individual situation in the sense of personalized medicine.
\end{abstract}

\section{Introduction}

Primary headache disorders are one of the most prevalent health problems worldwide. ${ }^{1}$ Even in the pediatric population headaches are among the most commonly reported health complaints. ${ }^{2-4}$ The prevalence of pediatric headache varies only slightly between different regions of the world. ${ }^{5}$ In

received

September 30, 2012

accepted

October 9, 2012

published online

January 9, 2013

a German survey, $83 \%$ of adolescents reported headache of any type and intensity level at least once per month, whereas a recent Swedish study revealed a 3-week prevalence in the same range. ${ }^{6,7}$ In a systematic review of population-based studies including children and adolescents, the calculated overall prevalence of headache between 1 month and lifetime was $58.4 \% .^{8}$ As in adults, the diagnosis of a primary

(c) 2013 Georg Thieme Verlag KG
Stuttgart · New York and Adolescence; Guest Editor, Florian Heinen, MD.
DOI http://dx.doi.org/ 10.1055/s-0032-1330856. ISSN 0174-304X. 
headache disorder in children and adolescents is assigned in accordance to the classification established by the International Headache Society (IHS). ${ }^{9}$ On the basis of these criteria, 7 to $10 \%$ of children and adolescents are considered to suffer migraine, up to $15 \%$ probable migraine, and 20 to $25 \%$ tensiontype headache $(\mathrm{TTH}) .{ }^{8,10-12}$ The reported 6-month prevalence of migraine or TTH in German grammar students is 10.2 and $48.7 \%$, respectively. Some $19.8 \%$ of the studied population experience a combination of migraine and $\mathrm{TTH}$, commonly encountered as mixed-type headache in the pediatric population. $^{13}$

Therapeutic approach consists of a multimodal program of pharmacotherapy, life-style intervention, psychoeducation, biobehavioral, and psychotherapeutic strategies as well as complementary measures individually composed for each patient. The range of applied interventions depends on the degree of disability and impairment of quality of life attributed to the headache as well as their availability. A variety of pharmacotherapeutic options have been established for the treatment of adult primary headaches. However, agreement on the pharmacologic strategy in children and adolescents is a particular challenge, because appropriate safety and efficacy data of many of those agents are limited or even missing for the pediatric population. In 2008, the German Migraine and Headache Society and the Society for Neuropediatrics published revised, evidence-based recommendations for the treatment of primary headache disorders in childhood (German National Guideline [GNG] 2008). ${ }^{14}$

The aim of this literature review is to provide an update on recent advances in pharmacotherapy of pediatric migraine and TTH since the publication of GNG 2008. Therefore, the literature concerning the topic published during the past 5 years was systematically reviewed. Given the wide range of drugs and their (in many cases) overlapping or only slightly varying profiles, this review does not grade the drugs hierarchically. On the basis of the outlined facts, the team of physician, patient, and parents needs to decide on the most appropriate regimen for the individual situation in the sense of personalized medicine. Complementary and biobehavioral treatment strategies are not the subject of this review.

\section{Methods}

MEDLINE and Cochrane Library were systematically searched for articles dealing with the treatment of pediatric headache published from January 2008 through June 2012. The following search commands were applied: pediatric AND headache treatment, acute or prevention or prophylactic treatment AND pediatric headache, migraine or tension-type headache AND treatment AND pediatric, migraine or tension-type headache AND prophylaxis AND pediatric. The language filter was set to English and German publications. The identified 587 titles and abstracts were reviewed for content and relevance to select those covering pharmacologic aspects of pediatric primary headache. In addition, checking the reference lists of the selected 68 articles for pertinent articles completed the bibliography. In total, 77 articles dealing with the subject of this update were reviewed in detail.
Articles were included to the bibliography if they fulfilled the following criteria:

1. Systematic review $(n=8)$; review $(n=27)$; clinical report $(n=33)$ : (randomized) controlled trial, uncontrolled trial, retrospective study or case report; report on pharmacokinetics $(n=1)$; report on clinical practice $(n=8)$.

2. Published between January 1, 2008, and June 30, 2012. The starting date was chosen to tie up to GNG 2008; June 2012 was the last full month before finalizing this review.

3. Reporting on a pediatric population suffering migraine or TTH.

4. The diagnosis of primary headache disorder was based on the IHS classification of 2004.

5. Reporting on pharmacotherapy of migraine or TTH.

Data collected from the clinical reports included (1) study design, (2) drug reported, (3) dosing and duration of medication, (4) efficacy and adverse events of medication, (5) indication reported on, (6) age group treated, (7) number of participants, (8) inclusion and exclusion criteria, (9) end points, and (10) statistical method used. We conducted the literature search, data collection, and analysis of the articles dealing with the update subject according to the principles of evidence-based medicine postulated by the Cochrane Collaboration. ${ }^{15}$ In addition to the outlined pediatric literature, the most recent guidelines and publications on future directions in treating adult primary headaches have been studied.

\section{Current Information}

\section{Treatment Principles}

In migraine attacks a fast reactive therapeutic approach is indicated. Acute therapy aims to relieve the symptoms as fast as possible to enable the patient to return to normal function within 1 to 2 hours without risk of relapse. ${ }^{16,17}$ In acute episodes of TTH a more defensive strategy is appropriate, as participation is usually not interrupted. The chosen medication has to ensure the most consistent response and the least side effects possible. ${ }^{18}$ To guarantee an optimized effect the patient must have quick access to the medication in any place and has to be thoroughly advised in the treatment strategy and application practice. ${ }^{19}$ Detailed clues for the symptomatic treatment in different settings are shown in -Tables 1-3.

Preventive therapy is indicated for patients suffering frequent migraine ( $>1$ to 2 per week or $>3$ to 4 per month) or experiencing headache-related disability that interferes with school attendance, daily routine, and daily activities (e.g., PedMIDAS $\geq 30$ ). ${ }^{20,21}$ Prophylaxis should also be considered if acute treatment options are ineffective, not tolerated, contraindicated, or regularly overused and in patients prone to extremely intensive, prolonged ( $>48$ hours), hemiplegic, or basilar-type migraine or severe aura. ${ }^{14,19,22}$ Prophylaxis can be appropriate in patients prone to frequent episodic TTH and should be discussed in patients suffering chronic TTH $(\mathrm{CTTH}){ }^{23,24}$ In general, pharmacologic prophylaxis is only 
Table 1 Detailed clues for the symptomatic treatment of headaches with analgesics and nonsteroidal antiinflammatory drugs

- Goals: fast relief of pain, return to normal activity, no relapse

- Take drug rapidly after onset (within $30 \mathrm{~min}$ )

- Dose adequately high for age and weight

- Repeat after 3-4 hours if necessary

- Do not exceed three times intake a week indicated if lifestyle modification and nonpharmacologic measures have been ineffective. ${ }^{19}$ Detailed clues for preventive treatment are displayed in - Table 4.

Every physician taking care of pediatric headache patients should be familiar with some key features of the pharmacologic treatment, as displayed in -Fig. $\mathbf{1}$.

\section{Symptomatic Treatment of Acute Episodes of Migraine and Tension-Type Headache}

Analgesics and Nonsteroidal Anti-inflammatory Drugs Concerning analgesic and anti-inflammatory treatment of

Table 2 Detailed clues for the symptomatic treatment of migraine with triptans ${ }^{\mathrm{a}}$

- Goals: fast relief of pain and associated symptoms, return to normal activity, no relapse, no progress of peripheral to central sensitization

- Consider different formulations (e.g., nasal spray, orally disintegrating tablet) in line with associated symptoms

- Exclude contraindications for triptans before prescription: vascular conditions (e.g., stroke, transient ischemic attack, hypertension, angina pectoris, myocardial infarction, peripheral artery occlusive disease, Raynaud syndrome), presence of vascular risk factors, intake of monoamine oxidase inhibitors (within 2 weeks) or ergotamines, impaired renal or liver function, pregnancy and lactation

- Do not generalize the whole triptan group: if one triptan does not show efficacy in a patient ( $\geq 3$ unresponsive episodes), try another as small differences in pharmacokinetic properties can be of clinical importance

- Two different triptan models ${ }^{53}$

- Rescue strategy: start with an NSAID in adequate dose at headache onset, use the triptan if relief is insufficient

- Stratified strategy: determine severity at headache onset, take NSAIDs or triptan if severity surpasses the individually determined triptan threshold (preferred by the authors)

- Repeat no more than once not before 2 hours after first dose and only if first dose did have an effect

- Do not exceed intake two times per week and six times per month ${ }^{18,20}$

- Patients prone to aura must not use triptans as long as aura symptoms are present but only if aura has dissolved and headache starts ${ }^{38}$

Abbreviation: NSAIDs, nonsteroidal anti-inflammatory drugs.

an case of insufficient experience in handling triptans, referral to a specialized center is indicated.

Table 3 Detailed clues for the emergency treatment of migraine ${ }^{a}$

- Goal: control of headache unresponsive to previous first-line/outpatient abortive treatment

- Choose agent in line with symptoms, previous therapy, and comorbidities

- Treat aggressively with adequate agent and dose

- Do not delay treatment

- Exclude contraindications before administering agents ${ }^{\mathbf{b}}$ :

- Acetylsalicylic acid: (pseudoallergic) asthma, gastrointestinal ulceration, impaired coagulation, heart failure, renal or liver failure, pregnancy; cave: febrile conditions in pediatric patients (Reye syndrome)

- Dopamine antagonists: extrapyramidal symptoms, epilepsy, prolactinoma, phaeochromocytoma, pregnancy

- Dihydroergotamine: see triptans + migraine of basilar or familiar hemiplegic type, vasculitis, porphyria, treatment with macrolid antibiotics, several HIV medications, azol-type mycotics or vasoconstrictors (including triptans!)

- Valproate: impaired hepatic or pancreatic function, hepatic disease (family anamnesis!), fatal liver failure in family, porphyria, impaired coagulation, insulin-depending diabetes

- Consider admission if parenteral "rescue" is necessary

- In any case, patients treated with parenteral dihydroergotamine should be admitted

- Discuss probability of headache recurrence with patients before discharge

- Educate patients in self-medication in case of recurrence

- Preventive medication with NSAIDs or steroids over the following days has not been established in pediatrics so far

Abbreviations: HIV, human immunodeficiency virus; NSAIDs, nonsteroidal anti-inflammatory drugs.

a Emergent treatment of exacerbated migraine should be reserved for experienced specialists.

bThe most relevant contraindications are listed. 
6 Pharmacotherapy of Pediatric Migraine and TTH Bonfert et al.

Table 4 Detailed clues for the preventive treatment of headaches

Goals:

- Reduction in headache severity parameters as set individually with the patient

- Migraine: i.e., frequency $<1-2 /$ month; PedMIDAS $<10$ (reflecting reduced disability and interference with daily activities)

- FTTH, CTTH: i.e., significant reduction of frequency and intensity of headaches

- CDH: i.e., intensity of every day headache $<5$ on the visual pain scale

- Reduction in frequency of use of acute treatment (avoidance of chronic overuse)

- Reduction in headache-related distress and psychological manifestations

- Improvement of overall quality of life (assessed by PedsQL)

Preventive regimen:

- Choose drug with regard to the patient's clinical features, comorbidities, and drug profiles

- Start at a low dose

- Titrate slowly over 4 (to 12 ) weeks

- If a trend of improvement is seen, adjust dose for optimal control

- If sustained, satisfying response is achieved, continue therapy for 4-6 months

- Wean slowly (not during stressful times, prefer vacations)

Problems:

- Onset of improvement is often delayed in children and adolescents: do not give up too early and educate patients on importance of adherence

- Incompliance is associated with poor response, higher risk of side effects, and worse overall prognosis

- Drug resistance is possible: if no or insufficient response is achieved after 12 weeks, switch to another agent; failure of one agent does not predict failure or success with any other

Abbreviations: $\mathrm{CDH}$, chronic daily headache; CTTH, chronic tension-type headache; FTTH, frequent episodic tension-type headache; PedMIDAS, pediatric migraine disability score.

acute headaches in children and adolescents, reviewing the current literature did not reveal any new pediatric data. Manzano et al provided a systematic review of trials comparing the effects of acetaminophen and ibuprofen in acute headaches, including only two historic pediatric trials. ${ }^{25}$ However, because these agents are the most frequently prescribed in pediatric headache therapy, their profiles are summarized below. Concerning acetylsalicylic acid, flupirtine, and nimesulide, no new pediatric data are available (-Table 5). Analgesic treatments only evaluated in adults so far, but with a putative benefit also for pediatric patients, are outlined in - Table 6.

Ibuprofen. Ibuprofen $(10 \mathrm{mg} / \mathrm{kg})$ is the first-line treatment for mild to severe attacks of migraine and for acute, infrequent episodes of TTH. Ibuprofen is superior to acetaminophen in having completely aborted migraine after 2 hours. ${ }^{14}$ Concerning grade of migraine pain relief 2 hours after drug ingestion, ibuprofen is slightly more effective than acetaminophen. Also, for acute TTH treatment ibuprofen seems to be more effective than acetaminophen in the sense of faster relief. ${ }^{25}$ In addition to an analgesic effect with good peak efficacy, ibuprofen is a reasonable choice due to its anti-inflammatory properties and ample therapeutic range. The authors dose ibuprofen up to $15 \mathrm{mg} / \mathrm{kg}$ in acute episodes.

Acetaminophen. Acetaminophen $(15 \mathrm{mg} / \mathrm{kg})$ is the secondline treatment of acute attacks of migraine and TTH. ${ }^{14}$ The use of acetaminophen should be considered if patients do not tolerate nonsteroidal anti-inflammatory drugs (NSAIDs) or suffer contraindications. ${ }^{20}$ The main advantage is the scarce peripheral cyclooxygenase inhibition with less adverse effects compared with NSAIDs in this respect. Time to peak level is shorter than that of ibuprofen (30 to 60 vs. 60 to 120 minutes), possibly leading to a faster onset of effect, but data are inconsistent in that concern. ${ }^{25}$ When prescribing patients with acetaminophen, the potential hepatic toxicity in cumulative self-medication must be kept in mind. In general, daily dosage must not exceed $60 \mathrm{mg} / \mathrm{kg}$, and dosing on sequent days should be avoided.

Triptans. In at least 30 to $60 \%$ of pediatric migraineurs, over-the-counter agents are only of minor value. ${ }^{26,27}$ These patients often benefit from migraine-specific treatment, currently limited to triptans, a group of selective serotonin receptor agonists at the $5-\mathrm{HT} 1 \mathrm{~B}$ and $1 \mathrm{D}$ receptor sites. ${ }^{18,26}$ Currently there are seven different triptans available to adult migraineurs. ${ }^{28}$ In pediatrics, four triptans have been recommended as agents (of second or third choice) for severe episodes unresponsive to analgesics. ${ }^{14}$ Current information on almotriptan, rizatriptan, sumatriptan, and zolmitriptan is given later and an overview of the corresponding trials is displayed in - Table 7. No novel pediatric data are available for eletriptan and naratriptan (-Table 5); frovatriptan has only been evaluated in adults so far (-Table 6). 


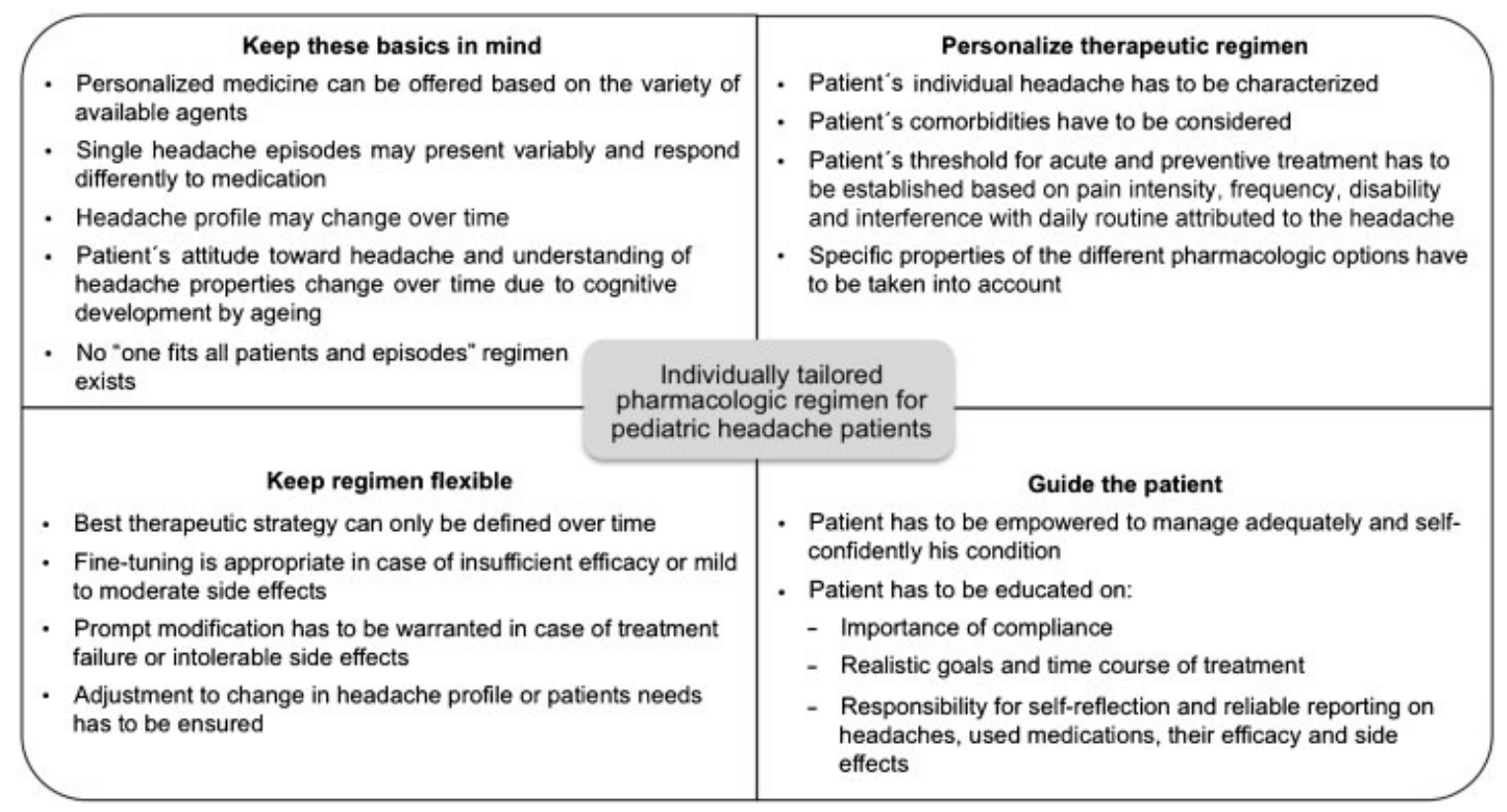

Fig. 1 Key features of the pharmacologic treatment of pediatric headache patients.

Almotriptan. GNG 2008 graded almotriptan (12.5 mg) as an alternative of third choice in migraine treatment due to limited evidence. ${ }^{14}$ Since then, important evidence concerning efficacy and safety in adolescent migraineurs emerged as Linder et al published their randomized, placebo-controlled, multicenter trial in 2008. Analyzing the data of 714 adolescents, this trial demonstrated almotriptan $(6.25,12.5$, and $25 \mathrm{mg}$ ) to be superior to placebo in regard to pain relief and pain freedom after 2 hours and sustained pain relief up to 24 hours. Findings were especially marked in the subgroup of 15- to 17-year-old adolescents. In the subgroup of 12- to 14-year-old patients, significance was not reached because of a higher placebo response rate. In addition, a significant improvement of photo- and phonophobia 2 hours after dosing was observed with 12.5-mg almotriptan but not with the two other doses. In general, almotriptan was well tolerated. These findings support the use of almotriptan in adolescent migraineurs, particularly at a dose of $12.5 \mathrm{mg}$ associated with the best efficacy profile. ${ }^{29}$ Based on these results, in 2009, the U.S. Food and Drug Administration (FDA) approved oral almotriptan (6.25 and $12.5 \mathrm{mg}$ ) for the treatment of migraine in adolescents ( $\geq 12$ years) suffering severe migraine attacks ( $\geq 4$ hours duration). The first triptan approved by the FDA for adolescents, currently almotriptan is rated a safe and effective treatment option for adolescents. ${ }^{30}$

Rizatriptan. Rizatriptan was one of the first oral triptans proven effective and safe in pediatric (aged $\geq 6$ years) migraine based on the trial of Ahonen et al in 2006. ${ }^{20}$ However, because of inconsistent data from two previous trials, GNG 2008 classified rizatriptan (5 and $10 \mathrm{mg}$ ) as an option of third choice in the treatment of pediatric migraine. ${ }^{14}$ Possible factors explaining the deviating results of the two other trials were a high placebo response rate, underdosing, population heterogeneity, and inadequate methods of efficiency assessment. ${ }^{27}$ In 2009 , Ho et al launched a randomized, placebo-controlled, multicenter trial with a double-blind, placebo, run-in design and a weightbased dosing regimen in line with the most recent pharmacokinetic findings stratified to minimize the cited confounders. ${ }^{31}$ Recently, the results of this trial were published: In 702 patients aged 12 to 17 years, rizatriptan was significantly superior to placebo in aborting pain, relieving pain (two grades on a five-face pain scale), and ensuring return to "normal function" within 2 hours after treatment as well as sustaining pain freedom up to 48 hours and aborting or preventing nausea or vomiting at the 2-hour time point. Even data concerning photo- and phonophobia at 2 hours after treatment and subjective satisfaction with medication favored rizatriptan without reaching significance. In 275 children aged 6 to 11 years, consistent findings were achieved in all aspects besides aborting or preventing vomiting. However, due to the limited sample size and statistical power, significance was not reached in this subgroup. In all age groups rizatriptan was well tolerated, and the rate of adverse events was similar in the rizatriptan and placebo groups. ${ }^{27}$ Based on this trial, the FDA approved rizatriptan oral tablets and orally disintegrating tablets ( 5 and $10 \mathrm{mg}$ ) for the acute treatment of migraine in children 6 years and older in December 2011.

Sumatriptan. Sumatriptan nasal spray $(10 \mathrm{mg})$ was the first triptan approved by the European Medicines Agency (EMA) in 2003 for the treatment of adolescent migraine. GNG 2008 graded sumatriptan nasal spray (10 and $20 \mathrm{mg}$ ) as the triptan of first choice for adolescents unresponsive to first-line overthe-counter drugs. ${ }^{14}$ In individual case use in younger children has been admitted, as studies have shown effectiveness and safety of nasal sumatriptan also in younger children ( $\geq 5$ years old). ${ }^{28}$ In recent years, no further trials evaluating nasal sumatriptan in pediatric migraine have been reported. Nevertheless, two recent case reports and one case series of children suffering periodic syndromes showed a good 
8 Pharmacotherapy of Pediatric Migraine and TTH Bonfert et al.

Table 5 Symptomatic and prophylactic drugs for pediatric primary headaches not addressed in clinical reports since $2008^{\mathrm{a} 14,38,46,77}$

\begin{tabular}{|c|c|c|}
\hline Drug & Evidence/drug profile/comments & $\begin{array}{l}\text { German National Guideline } 2008 \text { (GNG) })^{14} \\
\text { Authors' comments (A) }\end{array}$ \\
\hline \multicolumn{3}{|l|}{ Analgesics and NSAIDs } \\
\hline Nimesulide $(2.5$ mg/kg) & $\begin{array}{l}1 \text { RDBCO }(N=66)^{78} \text { : as effective as PCM in pain relief; most } \\
\text { widely spread NSAID in some European countries (Italy, France, } \\
\text { Greece) }\end{array}$ & $\begin{array}{l}\text { GNG: Not reported; } \\
\text { A: No advantage compared with other NSAID; risk of } \\
\text { hepatotoxicity in self-medicating patients }\end{array}$ \\
\hline Flupirtine (6-8 yr: $50 \mathrm{mg}$; 9-12 yr: $100 \mathrm{mg}$ ) & $\begin{array}{l}1 \text { RDBCO }(N=30) \text { : in TTH as effective as PCM; potent and safe } \\
\text { agent in acute and chronic pain states in adults; central acting } \\
\text { analgesic with normalizing effect on muscle tone }\end{array}$ & $\begin{array}{l}\text { GNG: Alternative to analgesics in TTH patients; } \\
\text { A: Alternative in TTH patients, if NSAID and PCM not } \\
\text { efficacious or contraindicated }\end{array}$ \\
\hline $\begin{array}{l}\text { ASS ( < } 12 \text { yr: } 10 \mathrm{mg} / \mathrm{kg} ; 25 \mathrm{mg} / \mathrm{kg} / \mathrm{d} ; \\
\geq 12 \text { yr: } 500-1,000 \mathrm{mg})\end{array}$ & $\begin{array}{l}1 \text { RDBPC }(N=638)^{24} \text { : Effective and safe in TTH patients }>15 \\
\text { yr; first-line option in adults; generally not recommended } \\
<12 \text { yr due to possible risk of Reye syndrome }\end{array}$ & $\begin{array}{l}\text { GNG: Treatment of further choice in adolescents; } \\
\text { A: Alternative in adolescents; cave: Reye syndrome } \\
\text { (ongoing controversy as a defined cause-effect } \\
\text { relationship is not supported by sufficient data }{ }^{79} \text { ) }\end{array}$ \\
\hline \multicolumn{3}{|l|}{ Migraine-specific drugs } \\
\hline Eletriptan (20 mg; 40-mg oral tablet) & $\begin{array}{l}1 \text { RDBPC }(N=274) \text { : Not superior to placebo in pain relief, } \\
\text { significantly lower 24-hr recurrence rate, well tolerated; alter- } \\
\text { native triptan in adults, fast onset of action (within } 30 \mathrm{~min} \text { ) }\end{array}$ & $\begin{array}{l}\text { GNG: Not rated due to limited evidence; } \\
\text { A: Further pediatric data needed }\end{array}$ \\
\hline Naratriptan (2.5-mg oral tablet) & $\begin{array}{l}1 \text { RDBPC }(N=300) ; 1 \text { ibuprofen-controlled trial }(N=40) \text { (only } \\
\text { abstract available) }{ }^{20} \text { : not superior to placebo, better pain relief } \\
\text { than ibuprofen, similar tolerability; alternative triptan in adult } \\
\text { migraine; onset of action later than other triptans (up to } 4 \mathrm{hr} \text { ), } \\
\text { lesser side effects }\end{array}$ & $\begin{array}{l}\text { GNG: Not rated due to limited evidence; } \\
\text { A: Further pediatric data needed }\end{array}$ \\
\hline Sumatriptan oral $(50 \mathrm{mg}, 100 \mathrm{mg})$ & $\begin{array}{l}1 \text { RDBPCCO }(N=23) \text { : Not superior to placebo in pain relief; first- } \\
\text { line triptan in adults, onset of action within } 60 \text { min; no differ- } \\
\text { ence in efficacy to nasal spray or suppositories }\end{array}$ & $\begin{array}{l}\text { GNG: Not rated due to limited evidence; } \\
\text { A: Further pediatric data needed }\end{array}$ \\
\hline DHE oral $(20-40 \mu \mathrm{g} / \mathrm{kg})$ & $\begin{array}{l}1 \text { RDBPCCO }(N=12) \text { : Better responder rate in DHE ( } 2 \text { doses) } \\
\text { than placebo (not significant); recurrence rate } 2 / 5 \text {; in adults } \\
\text { option of further choice as there is no advantage compared with } \\
\text { triptans, worse tolerability than triptans, high risk of rebound } \\
\text { headache and risk of abuse }\end{array}$ & $\begin{array}{l}\text { GNG: Alternative of further choice; } \\
\text { A: Oral administration is of limited value due to } \\
\text { interference with migraine and DHE associated nausea }\end{array}$ \\
\hline \multicolumn{3}{|l|}{ Oral antiemetics } \\
\hline Dimenhydrinate $(1-2 \mathrm{mg} / \mathrm{kg})$ & No trials; relevant side effect: sedation & \multirow{3}{*}{$\begin{array}{l}\text { GNG: No pediatric data available; all agents are possible } \\
\text { options in patients suffering gastrointestinal symptoms; } \\
\text { A: Patients suffering disabling nausea or refusing intake } \\
\text { of drugs due to nausea can profit of antiemetics; if } \\
\text { patients vomit only once or pain is relieved after } \\
\text { vomiting, antiemetics are not indicated }\end{array}$} \\
\hline $\begin{array}{l}\text { Domperidone }(1 \mathrm{mg} / \mathrm{kg}) \\
\text { Metoclopramide }(0.1-0.2 \mathrm{mg} / \mathrm{kg})\end{array}$ & $\begin{array}{l}\text { No trials; reasonable in patients with gastroparesis, may lead to } \\
\text { increased absorption of drugs; relevant side effect: extrapyra- } \\
\text { midal symptoms }\end{array}$ & \\
\hline $\begin{array}{l}\text { Ondansetron }(0.1-0.15 \mathrm{mg} / \mathrm{kg}) \\
\text { Granisetron }(0.01-0.05 \mathrm{mg} / \mathrm{kg})\end{array}$ & $\begin{array}{l}\text { No trials; good efficacy and tolerability profile of ondansetron, } \\
\text { but potential interaction with PCM to be considered (reduced } \\
\text { efficacy of PCM); relevant side effect: dizziness, sedation }\end{array}$ & \\
\hline \multicolumn{3}{|l|}{ Emergency treatment } \\
\hline Ketorolac IV $(0.5 \mathrm{mg} / \mathrm{kg}$, max. $30 \mathrm{mg})$ & $1 \mathrm{RDB}(N=62)^{20}: 55 \%$ responder rate, recurrence $30 \%$; NSAID & $\begin{array}{l}\text { GNG: Not reported; } \\
\text { A: To be considered in acute migraine and TTH } \\
\text { unresponsive to over-the counter analgesics }\end{array}$ \\
\hline Sumatriptan SC (0.05-0.2 mg/kg; max. 6 mg) & $\begin{array}{l}2 \text { OLCS }(N=50 ; 17) \text { : possibly effective and safe option; onset of } \\
\text { action within } 10 \text { min but more side effects compared with other } \\
\text { sumatriptan formulations }\end{array}$ & $\begin{array}{l}\text { GNG: Alternative in severe migraine attacks; } \\
\text { A: Orally disintegrating tablets preferred, needle-free } \\
\text { device possible future option (Sumavel) }\end{array}$ \\
\hline \multicolumn{3}{|l|}{ Prophylaxis } \\
\hline Levetiracetam (20-40 mg/kg) & $\begin{array}{l}\text { Migraine: } 1 \text { OLCS }(N=20) ; 1 \text { RCR }(N=19) \text { : up to } 90 \% \text { re- } \\
\text { sponder rate; side effects in } 15 \% \text { of patients; not effective in } \\
\text { adults }\end{array}$ & $\begin{array}{l}\text { GNG: Not rated due to limited evidence; } \\
\text { A: Not reasonable (inefficacy in adults, side effects) }\end{array}$ \\
\hline Zonisamide $(3-10 \mathrm{mg} / \mathrm{kg})$ & $\begin{array}{l}\text { Chronic headache: } 1 \text { RCR }(N=12) \text { : responder rate } 87,5 \% \text {; } \\
\text { promising results in adult migraine, confirmation needed }\end{array}$ & $\begin{array}{l}\text { GNG: Not rated due to limited evidence; } \\
\text { A: Further pediatric data needed }\end{array}$ \\
\hline ASS (2-3 mg/kg) & $\begin{array}{l}\text { Migraine: } 1 \text { RDB }(N=30) \text { : as effective as flunarizine; second line } \\
\text { in adult migraine; relevant side effect: increased risk of bleeding; } \\
\text { generally not recommended }<12 \text { yr due to possible risk of } \\
\text { Reye syndrome }\end{array}$ & $\begin{array}{l}\text { GNG: Second-line option with respect to } \\
\text { contraindications; } \\
\text { A: Alternative in adolescents; cave: side effects (ongoing } \\
\text { controversy on Reye syndrome as a defined cause-effect } \\
\text { relationship is not supported by sufficient data }{ }^{79} \text { ) }\end{array}$ \\
\hline Pizotifen $(0.5-0.75 \mathrm{mg})$ & $\begin{array}{l}\text { Migraine: } 1 \text { RDBPCCO }(N=47)^{78} \text { : no significant difference to } \\
\text { placebo }\end{array}$ & $\begin{array}{l}\text { GNG: Not reported; } \\
\text { A: Not recommended }\end{array}$ \\
\hline \multicolumn{3}{|c|}{ Not effective in pediatric or adult preventive trials } \\
\hline \multicolumn{2}{|c|}{ Clonidine, fluoxetine, nimodipine, trazadone, 5-hydroxy-tryptophan, papaverin ${ }^{19}$} & $\begin{array}{l}\text { GNG: Not recommended; } \\
\text { A: Not recommended }\end{array}$ \\
\hline
\end{tabular}

Abbreviations: ASS, acetylsalicylic acid; DHE, dihydroergotamine; IV, intravenous; kg, kilogram body weight; NSAIDs, nonsteroidal anti-inflammatory drugs; OLCS, open-label case series; PCM, paracetamol; RCR, retrospective chart review; RDB, randomized double-blind trial; RDBCO, randomized, double-blind, crossover trial; RDBPC, randomized, double-blind, placebo-controlled trial; RDBPCCO, randomized, double-blind, placebo-controlled, crossover trial; SC, subcutaneous; TTH, tension-type headache.

alf not differently indicated, the listed trials have been cited in GNG 2008. 
Table 6 Selection of drugs only established or evaluated in adults so far for the acute and preventative treatment of primary headaches ${ }^{\mathrm{a} 38,46,57,77}$

\begin{tabular}{|c|c|c|c|}
\hline Drug (adult dose) & Drug profile & Adult recommendations & Authors' comments \\
\hline \multicolumn{4}{|l|}{ Analgesics and NSAIDs } \\
\hline $\begin{array}{l}\text { Naproxen sodium } \\
(250-500 \mathrm{mg})\end{array}$ & $\begin{array}{l}\text { Effective pain relief, time to peak level } \\
60 \mathrm{~min} \text {, half-life }>12 \mathrm{hr}\end{array}$ & $\begin{array}{l}\text { Alternative in acute migraine and } \\
\text { TTH }\end{array}$ & $\begin{array}{l}\text { Reasonable alternative in } \\
\text { adolescents due to overall } \\
\text { profile }\end{array}$ \\
\hline $\begin{array}{l}\text { Diclofenac potassium } \\
\text { water-soluble powder } \\
\text { formulation }(50 \mathrm{mg})\end{array}$ & $\begin{array}{l}\text { In migraine superior to placebo and } \\
\text { diclofenac tablets in pain relief }{ }^{21} \text {; time } \\
\text { to peak plasma level } 15 \text { min; fast pain } \\
\text { relief (within } 30 \text { min); sustained effect } \\
\text { up to } 24 \mathrm{hr}\end{array}$ & $\begin{array}{l}\text { No report on powder formulation; } \\
\text { diclofenac (oral tablet) is a first-line } \\
\text { option for TTH }\end{array}$ & $\begin{array}{l}\text { Promising option, to be } \\
\text { considered in adolescents } \\
\text { with migraine and TTH due } \\
\text { to overall profile }\end{array}$ \\
\hline $\begin{array}{l}\text { Combination of paracetamol } \\
+ \text { caffeine }(1,000+130 \mathrm{mg})\end{array}$ & $\begin{array}{l}\text { In TTH superior to placebo and } \\
\text { paracetamol monotherapy }{ }^{24} ; \text { direct } \\
\text { and adjuvant analgesic effects of } \\
\text { caffeine are discussed }\end{array}$ & First-line option for acute TTH & $\begin{array}{l}\text { Possible option in } \\
\text { adolescents } \geq 16 \mathrm{yr}\end{array}$ \\
\hline \multicolumn{4}{|l|}{ Migraine-specific drugs } \\
\hline $\begin{array}{l}\text { Frovatriptan } \\
\text { (2.5-mg oral tablet) }\end{array}$ & $\begin{array}{l}\text { One pharmacokinetics and tolerability } \\
\text { study in adolescents demonstrated } \\
\text { similar profile to adults; probably no } \\
\text { dosage adjustment necessary }{ }^{28} \text {; late } \\
\text { onset of action (up to after } 4 \text { hr), fewer } \\
\text { side effects than other triptans }\end{array}$ & Alternative in acute migraine & $\begin{array}{l}\text { Further pediatric data } \\
\text { needed }\end{array}$ \\
\hline $\begin{array}{l}\text { Sumatriptan transdermal } \\
\text { patch (Zelrix) }\end{array}$ & $\begin{array}{l}\text { Delivery of consistent triptan plasma } \\
\text { levels over } 4 \mathrm{hr} \text {, independently of } \\
\text { gastrointestinal symptoms }\end{array}$ & Not reported; expensive option & $\begin{array}{l}\text { Interesting option, pediatric } \\
\text { data needed }\end{array}$ \\
\hline $\begin{array}{l}\text { DHE oral inhalation } \\
\text { (Levadex) }\end{array}$ & $\begin{array}{l}\text { Outpatient use, fast onset of action, } \\
\text { sustained effect, good tolerability }{ }^{80}\end{array}$ & Not reported & $\begin{array}{l}\text { Interesting option for } \\
\text { nonresponders to triptans, } \\
\text { pediatric data needed, cave: } \\
\text { side effects, abuse }\end{array}$ \\
\hline $\begin{array}{l}\text { Calcitonin gene-related } \\
\text { peptide antagonists }\end{array}$ & $\begin{array}{l}\text { Further research on telcagepant } \\
\text { suspended due to risk of hepatic } \\
\text { toxicity; other research compounds } \\
\text { currently studied; not available on the } \\
\text { market yet }^{80}\end{array}$ & Not rated yet & $\begin{array}{l}\text { Pediatric data needed if } \\
\text { approved for adults }\end{array}$ \\
\hline \multicolumn{4}{|l|}{ Emergency treatment } \\
\hline ASS IV (1,000 mg) & $\begin{array}{l}\text { Fast onset of action, high efficacy, } \\
\text { good tolerability; generally not } \\
\text { recommended }<12 \text { yr due to } \\
\text { possible risk of Reye syndrome }\end{array}$ & $\begin{array}{l}\text { First-line option in emergency } \\
\text { setting of acute migraine }\end{array}$ & $\begin{array}{l}\text { Consider as option in } \\
\text { adolescent migraineurs; } \\
\text { cave: Reye syndrome } \\
\text { (ongoing controversy as a } \\
\text { defined cause-effect } \\
\text { relationship is not supported } \\
\text { by sufficient data }\end{array}$ \\
\hline Metamizole IV (1,000 mg) & $\begin{array}{l}\text { Effective in aborting acute migraine; } \\
\text { relevant side effects: hypotension, } \\
\text { agranulocytosis }\end{array}$ & $\begin{array}{l}\text { Alternative in emergency setting of } \\
\text { acute migraine }\end{array}$ & $\begin{array}{l}\text { Consider as option in } \\
\text { adolescent migraineurs }\end{array}$ \\
\hline $\begin{array}{l}\text { Dexamethasone }(10 \mathrm{mg}) \\
\text { Prednisone }(50-100 \mathrm{mg})\end{array}$ & $\begin{array}{l}\text { Possibly effective in status migraino- } \\
\text { sus and for prevention of recurrence } \\
\text { after exacerbated migraine attacks }\end{array}$ & $\begin{array}{l}\text { Expert consensus favors use of } \\
\text { steroids, despite inconsistent data }\end{array}$ & Pediatric data needed \\
\hline \multicolumn{4}{|l|}{ Prophylaxis } \\
\hline Gabapentin (900-2,400 mg) & $\begin{array}{l}\text { Advantage: fast titration possible, } \\
\text { benefit in severely disabled patients } \\
\text { with migraine and TTH }\end{array}$ & $\begin{array}{l}\text { Second line in adult migraine } \\
\text { Further choice in adult TTH }\end{array}$ & Pediatric data needed \\
\hline Mirtazapine (15-30 mg) & $\begin{array}{l}\text { Specific noradrenergic and serotonin- } \\
\text { ergic antidepressant }\end{array}$ & First line in adult TTH & Pediatric data needed \\
\hline Tizanidine (4-16 mg) & $\begin{array}{l}\text { Central acting muscle relaxant, } \\
\text { reasonable in patients with } \\
\text { tenderness of pericranial muscles }\end{array}$ & First line in adult TTH & Pediatric data needed \\
\hline
\end{tabular}

Abbreviations: ASS, acetylsalicylic acid; DHE, dihydroergotamine; IV, intravenous; NSAIDs, nonsteroidal anti-inflammatory drugs; TTH, tension-type headache.

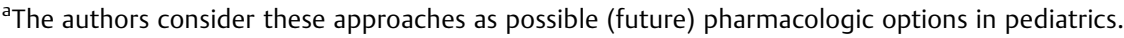


Table 7 Symptomatic drugs for the acute treatment of pediatric primary headaches addressed in clinical reports since 2008

\begin{tabular}{|c|c|c|c|}
\hline Reference & Indication & Drug (dosage) & $\begin{array}{l}\text { Study design, number of patients }(N) \text {, } \\
\text { age of patients, and study period (SP) }\end{array}$ \\
\hline 29 & M & Almotriptan $(6.25,12.25,25 \mathrm{mg})$ & $\begin{array}{l}\text { RDBPC; } N=866(\mathrm{R}), 714(\mathrm{ITT}) \\
12-17 \text { yr; SP: } 1 \text { migraine attack }\end{array}$ \\
\hline 27 & M & Rizatriptan ( < 40 kg: 5 mg; $\geq 40$ kg: 10 mg) & $\begin{array}{l}\text { RDBPC; } N=1382 \text { (R), } 977 \text { (ITT); } \\
\text { 6-17 yr; SP: } 1 \text { migraine attack }\end{array}$ \\
\hline 33 & AM & Nasal sumatriptan (20 mg) & $\mathrm{CR} ; N=2 ; 9,12 \mathrm{yr}$ \\
\hline 32 & CVS & Nasal sumatriptan (20 mg) & $C R ; N=1 ; 14 \mathrm{yr}$ \\
\hline 34 & CVS & Nasal sumatriptan (20 mg) & $\begin{array}{l}\text { OLCS; } N=5 \text { (6 attacks of CVS); } \\
4-24 \mathrm{yr}\end{array}$ \\
\hline 36 & M & $\begin{array}{l}\text { Sumatriptan + naproxen (10/60; 30/180; } 85 / \\
500 \text { mg) }\end{array}$ & $\begin{array}{l}\text { RDBPC; } N=656(R), 490 \text { (ITT); } \\
12-17 \text { yr; SP: } 1 \text { migraine attack }\end{array}$ \\
\hline 37 & M & Sumatriptan + naproxen (85/500 mg) & $\begin{array}{l}\text { OL; } N=656 \text { (enrolled), } 591 \text { (ITT); } \\
12-17 \text { yr; SP: } 12 \text { mo }\end{array}$ \\
\hline 34 & CVS & Subcutaneous sumatriptan (1-3 mg) & $\begin{array}{l}\text { OLCS; } N=11 \text { (35 attacks of CVS); } \\
4-24 \text { yr }\end{array}$ \\
\hline 47 & SM & $\begin{array}{l}\text { Metoclopramide/chlorpromazine (not } \\
\text { specified) }\end{array}$ & RCR; $N=184$ (187 events); 8-17 yr \\
\hline 48 & SM & Prochlorperazine $(0.15 \mathrm{mg} / \mathrm{kg}$; max. $10 \mathrm{mg})$ & $\begin{array}{l}\text { RCR; } N=92 \text { episodes of migraine; } \\
7-17 \mathrm{yr}\end{array}$ \\
\hline 49 & SM & Prochlorperazine $(0.15 \mathrm{mg} / \mathrm{kg}$; max. $10 \mathrm{mg})$ & $\begin{array}{l}\text { OLCS; } N=79 \text { (64 with confirmed } \\
\text { diagnosis); } 13.6 \pm 2.3 \mathrm{yr}\end{array}$ \\
\hline 50 & ACM & Prochlorperazine (5-10 mg) & CR; $N=2$ (6 episodes); 11,16 yr \\
\hline 40 & SM & $\begin{array}{l}\text { Prochlorperazine/mectoclopramide + ketoro- } \\
\text { lac (not specified) }\end{array}$ & RCR; $N=297 ;$ age not specified \\
\hline 51 & SM & $\begin{array}{l}\text { Dihydroergotamine ( }<25 \mathrm{~kg} \text { or } \leq 9 \mathrm{yr}: 0.5 \mathrm{mg} \text {; } \\
\geq 25 \mathrm{~kg} \text { or age }>9 \mathrm{yr}: 1 \mathrm{mg} \text {; every } 8 \mathrm{hr} \text { over } \\
3 \text { min; max. } 20 \text { doses) }\end{array}$ & $\mathrm{RCR} ; N=32 ; 14.52 \pm 1.91 \mathrm{yr}$ \\
\hline 52 & ACM & Valproate $(20 \mathrm{mg} / \mathrm{kg})$ & $\mathrm{CR} ; N=1 ; 12 \mathrm{yr}$ \\
\hline
\end{tabular}

Abbreviations: ACM, acute confusional migraine; AM, abdominal migraine; CG, control group; CR, case report; CVS, cyclic vomiting syndrome; ITT, intention to treat; kg, kilogram body weight; M, migraine; OL, open-label trial; OLCS, open-label case series; R, randomized; RCR, retrospective chart review; RDBPC, randomized, double-blind, placebo-controlled trial; SM, status migrainosus.

response to intranasal sumatriptan. ${ }^{32-34}$ Regarding oral administration, up to 2008 efficacy could not be proven and there are no new data available ${ }^{14,28}$ (- Table 5).

Zolmitriptan. GNG 2008 rated zolmitriptan orally disintegrating tablet $(2.5 \mathrm{mg}$ ) and nasal spray (5 mg) as a drug of third choice for the treatment of pediatric migraine. ${ }^{14}$ Since then no novel data have been published, but zolmitriptan nasal spray ( 2.5 and $5 \mathrm{mg}$ ) has been approved by the EMA in 2009 for treating acute migraine episodes in adolescents ( $\geq 12$ years). This approval was based on the results of a randomized, placebo-controlled, crossover, multicenter trial by Lewis et al published in 2007. ${ }^{18,20}$

\section{Combination of a Triptan and an Analgesic/NSAIDs or Prokinetic}

In some patients, the goal of consistent, complete, and rapid relief of migraine attacks is not achieved with monotherapy of any type. In those patients, combination therapy may be reasonable. $^{20}$ First, a significant benefit may be achieved in combining drugs with different pharmacodynamics, as migraine is a condition with several pathophysiologic traits. Second, combinations could target associated migraine symptoms, and, third, lower doses of each agent may be sufficient due to synergistic effects. ${ }^{26}$ Hence, in adults this approach is regarded as a reasonable treatment option shown to be effective and safe in various trials. ${ }^{18}$ Different combinations are established (e.g., triptan + NSAID, triptan + prokinetic), and some are already available in fixed formulations (e.g., sumatriptan plus naproxen). ${ }^{35}$ At this time pediatric evidence is limited to data for the combination of sumatriptan with naproxen in adolescents (-Table $\mathbf{7}$ ).

Sumatriptan combined with naproxen (suma/nap). By treating adult migraine with suma/nap better results can be yielded concerning superior efficacy, enhanced medication satisfaction, and improved quality of life compared with its components' monotherapy. ${ }^{36}$ Recently Derosier et al published the results of their large, randomized, placebocontrolled, multicenter trial dealing with the efficacy and safety of suma/nap in adolescents. Data from 490 patients randomized to placebo or one of three different combination 
dosages $(10 / 60,30 / 180$, and $85 / 500 \mathrm{mg}$ ) are provided. All dosages demonstrated superior efficacy to placebo in 2-hour pain-free rates without differences between the dosing subgroups. The $85 / 500$ dosing was superior to placebo in sustaining pain freedom and in photo- and phonophobia freedom at 2 hours. Additionally, all secondary end points apart from pain freedom at 1 hour and nausea freedom at 2 hours favored the combination over placebo. Numerically, the other doses showed similar trends, except for nausea at 2 hours, where only the lowest dose showed a significantly better response rate than placebo. In 12- to 14-year-old patients $10 / 60 \mathrm{mg}$ dosing trended to faster pain relief and better overall efficacy, whereas $85 / 500 \mathrm{mg}$ dosing showed comparable or numerically higher response rates in 15- to 17year-old adolescents. However, the maximum dose was more frequently related to nausea, particularly in 12- to 14-year-old migraineurs, leading to lower satisfaction with side effects. The high dosing trended to better efficacy at later time points compared with the lower doses. Generally, all three doses were safe and well tolerated. In summary, suma/nap 10/60 mg seems appropriate for younger patients and patients with brief episodes, whereas 85/500 mg seems more appropriate for older patients and patients suffering long-lasting episodes or those at risk of recurrence. ${ }^{36}$ Concerning long-term effects of suma/nap, McDonald et al confirmed a good tolerability profile, a high grade of satisfaction with the treatment regimen, and positive effects on the quality of life in 591 adolescents. Overall, pain freedom within 2 hours was reported in $42 \%$ of the treated episodes. ${ }^{37}$

\section{Authors' Comments on Triptans}

Currently, oral almotriptan and rizatriptan and nasal sumatriptan and zolmitriptan are proven effective and safe options in treating pediatric migraine. For oral eletriptan, naratriptan, and sumatriptan no new data have been published since 2008 , and for frovatriptan pediatric data are missing at all. Selection of the specific triptan depends on the individual setting. Eletriptan and rizatriptan exert their effects after 30 minutes, almotriptan or oral zolmitriptan after 45 to 60 minutes, and naratriptan or frovatriptan in up to 4 hours. Nasal formulations are supposed to act faster than their oral analogues. Regarding pain relief after 2 hours in adults, eletriptan is the most effective triptan, followed by rizatriptan, followed by oral almotriptan, sumatriptan, and zolmitriptan. Naratriptan and frovatriptan are inferior to oral sumatriptan in this outcome measure but similarly effective after 4 hours. On the other hand, eletriptan tends to cause more side effects than the other triptans, whereas naratriptan and frovatriptan are reported to be better tolerated than sumatriptan. Moreover, triptan profiles differ in recurrence rates ( 15 to $40 \%$ ) depending on half-life. ${ }^{38}$ Regarding formulations, the use of oral tablets might be limited if gastroparesis or nausea and vomiting are associated symptoms. Disintegrating tablets are likely to be better accepted by those patients, but a benefit concerning speed of onset does not exist. Intranasal applications are another alternative, but some patients refuse to use them due to a displeasing sensation and disturbance of taste. A novel transdermal patch technique may be a convenient, but so far expensive, option in the future
(-Table 6). Several patients may benefit from combining triptans with NSAIDs or prokinetics as an enhanced overall outcome and satisfaction by offering a logical and optimal timed combination is expected. ${ }^{26}$ Other than sumatriptan and naproxen, the combination of rizatriptan (fast onset of action) with naproxen (sustained effect) seems reasonable.

Migraine-Specific Treatment Options other than Triptans Regarding orally administered dihydroergotamine (DHE) no new trials have been reported (- Table 5). For alternative DHE formulations so far no pediatric-specific data have been published, as for the group of calcitonin gene-related peptide

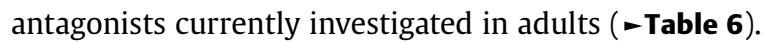

\section{Adjuvant Antiemetics}

Currently, no novel pediatric data on the coadministration of oral antiemetics have been published (- Table 5).

\section{Emergency Treatment of Acute Episodes of Migraine and Tension-Type Headache}

Acute headache is often (between 1 and 3\% of visits) encountered in pediatric emergency departments (EDs). ${ }^{39,40}$ In about 40 to $60 \%$ a first episode or exacerbation of primary headache accounts for the visit, with up to 70 and $20 \%$ due to migraine and TTH, respectively. ${ }^{39,41}$ Because of the limited data available on pediatric emergent treatment, no definitive recommendations could be given in $2008 .^{14}$ Until recently exacerbated migraine has rarely been addressed in pediatric controlled trials, and exacerbated TTH has not been investigated at all. Novel data are available on parenteral dopamine antagonists and DHE for exacerbated migraine, subcutaneous sumatriptan for severe cyclic vomiting syndrome (CVS), and one case report of valproate (VPA) in confusional migraine (-Table 7). Agents not addressed in clinical reports since 2008 are listed in - Table 5; - Table 6 provides approaches only evaluated in adults so far that could be reasonable options in pediatric patients.

Analgesics. Next to the oral outpatient options for patients still naive to them, parenteral analgesics are a commonly chosen option. ${ }^{42,43}$ of the available drugs only the NSAID ketorolac was studied in the past. ${ }^{44,45}$ No pediatric efficacy data are available on other parenteral analgesics, including acetylsalicylic acid and metamizole. (Parenteral) opioids should not be administered to pediatric migraineurs because they are inferior to migraine-specific agents and of limited benefit in adults. ${ }^{38,42-44}$

Triptans. In patients naive to triptans, these are the firstline option next to analgesics in the emergency setting. In adults subcutaneous sumatriptan is one of the first-line strategies. $^{38}$ GNG 2008 graded subcutaneous sumatriptan as an option for status migrainosus. ${ }^{14}$ Since then no new data were reported for this indication. In children suffering severe CVS one uncontrolled, open trial evaluating subcutaneous sumatriptan ( 1 to $3 \mathrm{mg}$ ) in 11 patients was published. Treatment was associated with a good to complete relief of symptoms in $54 \%$ of the treated episodes. ${ }^{34}$

Dopamine antagonists. Parenteral dopamine antagonists (e.g., metoclopramide, chlorpromazine, prochlorperazine) 
are effective abortive substances in the treatment of adult migraine and the most often used agents in the treatment of refractory migraine in pediatric EDs. ${ }^{43,46}$ Parenteral dopamine antagonists enhance migraine symptoms in two pharmacodynamic ways: in the sense of a specific antimigraine effect by interfering with the dopaminergic system and by positively influencing associated nausea and vomiting. GNG 2008 did not report on parenteral dopamine antagonists. ${ }^{14}$ By 2008, prochlorperazine was shown efficacious and safe in a randomized, controlled trial and two openlabel trials demonstrating responder rates up to $85 \%$ but considerable recurrence rates (30\%). ${ }^{45}$ Recently, Legault et al demonstrated efficacy and safety of metoclopramide and chlorpromazine in 184 patients suffering status migrainosus analyzed retrospectively. Recurrence rates in 1 month were $11 \%{ }^{47}$ Similarly, a retrospective chart review of 92 severe acute migraine episodes treated in the ED resulted in good efficacy and tolerability of prochlorperazine $(0.15 \mathrm{mg} / \mathrm{kg}$ intravenously to a maximum of $10 \mathrm{mg}$ ). Treatment failure was observed in $14 \%$ of patients. ${ }^{48}$ In their prospective, open-label cohort including 64 patients, Trottier et al confirmed the excellent efficacy profile (fast pain relief) with only a low number of primary treatment failure events (need of rescue therapy in 9\% of patients). However, 68\% of patients reported relapse of symptoms during 7 days, which made $12 \%$ of patients return to the ED. Sixty-seven percent of relapsing patients were taking NSAIDs intended to prevent recurrence (mostly naproxen). ${ }^{49}$ Moreover, prochlorperazine aborted the symptoms in two cases of acute confusional migraine. ${ }^{50}$ Dopamine antagonists generally bear the risk of extrapyramidal symptoms (in most cases orofacial hyperkinesias and acute dystonic reactions). In adults akathisia is observed in 36 to $44 \%$, but by coadministering diphenhydramine $(0.5 \mathrm{mg} / \mathrm{kg}$ intravenously, maximum $25 \mathrm{mg}$ ) the incidence can be reduced to $14 \%$. Despite the adjunctive diphenhydramine prophylaxis, 5 and 34\% of patients were diagnosed as definitive and possible akathisia, respectively in the trial of Trottier et al. ${ }^{49}$ Up to this report the incidence was probably underestimated mainly due to insufficient registration. Thus, extrapyramidal symptoms can occur despite diphenhydramine prophylaxis. This side effect needs to be thoroughly discussed with the patients, and in case of acute dystonic reaction a dose of diphenhydramine $(0.5 \mathrm{mg} / \mathrm{kg}$ intravenously, maximum $25 \mathrm{mg})$ is indicated and in general sufficient, even if diphenhydramine prophylaxis has been given previously.

Dopamine antagonist in combination with NSAIDs. The parenteral combination of a dopamine antagonist and NSAIDs is highly efficacious in the treatment of adult migraine and is increasingly prescribed in pediatrics. ${ }^{20,43}$ Kabbouche et al retrospectively rated prochlorperazine as well as metoclopramide plus ketorolac effective as 78\% of 297 episodic migraineurs were pain free at discharge. Unfortunately, no data concerning recurrence rate have been reported. ${ }^{40}$

Dihydroergotamine. In adults parenteral DHE was the rescue agent for aborting status migrainosus for a long time but is no longer on the markets in all countries. Based on previous data of one retrospective report of a low-dose DHE regimen GNG 2008 recommended DHE (maximum, $4 \times 0.2 \mathrm{mg}$ ) as an option in emergent situations. ${ }^{14}$ In 2009 , Kabbouche et al provided a pediatric high-dose protocol, retrospectively evaluated in their clinic. Patients received repeated doses of DHE $(<25 \mathrm{~kg}$ or $\leq 9$ years: $0.5 \mathrm{mg}$; $\geq 25 \mathrm{~kg}$ or age $\geq 9$ years: $1 \mathrm{mg}$; every 8 hours over 3 minutes). Response was rated only after the injection of the fifth dose. If improvement was indicated, infusions were continued until headache freedom or a maximum number of 20 doses were reached. Headache freedom was achieved in 40 and $67 \%$ of 32 patients after dose 5 and doses 12 and 13, respectively. At discharge, $74 \%$ of patients were headache-free. One patient discontinued therapy due to headache worsening by dose 5 , and two patients dropped out due to side effects. ${ }^{51}$ Pediatricians must be aware of the side effects of DHE (severe nausea, anxiety) that can aggravate migraine symptoms in the first instance. Therefore, comedication with antiemetics and adequate hydration are necessary. Moreover, DHE is contraindicated in pregnant females and no triptan should have been administered in the past 24 hours. Test dosing (initial injection of a half dose) is advisable, with continuation of injection after 30 minutes if test dose was well tolerated. To minimize the risk of relapse one additional dose of DHE may be administered after pain freedom is achieved. ${ }^{20,51}$

Valproate. In adults parenteral VPA has been studied as a treatment option for status migrainosus with promising results. $^{38,46}$ GNG 2008 described VPA (15 to $20 \mathrm{mg} / \mathrm{kg}$ in 5 minutes) as a possible alternative for status migrainosus based on limited data of one open trial. ${ }^{14}$ Since then only one case report dealing with VPA was published. A 12-year-old girl suffering acute confusional migraine responded rapidly and completely to VPA, and no recurrence was observed. ${ }^{52}$ Two VPA protocols have been reported in the literature. The first was a VPA bolus (15 to $20 \mathrm{mg} / \mathrm{kg}$ intravenously over 5 minutes) followed by an oral dose (15 to $20 \mathrm{mg} / \mathrm{d}$ ) within 4 hours. The second was a parenteral VPA bolus ( $15 \mathrm{mg} / \mathrm{kg}$ over 5 minutes), followed by $5 \mathrm{mg} / \mathrm{kg}$ intravenously every 8 hours until headache freedom or a maximum of 10 doses was reached. ${ }^{53}$

\section{Authors' Comments on Emergency Treatment}

For the treatment of exacerbated migraine several strategies need to be discussed in the individual setting. Parenteral analgesics monotherapy can be worthy of a trial, particularly acetylsalicylic acid because it is regarded as highly effective in adults. Subcutaneous sumatriptan is an effective rescue strategy in exacerbated migraine. However, the use of oral rizatriptan offers an alternative, as differences in time to onset of action seem acceptable (10 vs. 30 minutes) and side effect profile is better. Oral application is more likely to be accepted by patients than subcutaneous injection. However, in severe episodes of CVS when there is refusal to take a tablet, subcutaneous sumatriptan may be a beneficial option. In adults a new needle-free subcutaneous application device has been approved recently, but the patient may still notice a short stitching pain. Pediatric data on this device are missing so far. Furthermore, in migraine otherwise not adequately relieved or if other agents are contraindicated parenteral dopamine antagonists are an option. However, the risk of acute 
dystonic reaction has to be taken seriously, particularly in patients younger than 12 years. Despite the paucity of data, DHE should be made available for patients with otherwise intractable status migrainosus (e.g., order on behalf of an international pharmacy in specialized centers). If DHE is ineffective or contraindicated, parenteral VPA could be an alternative. After successful emergent treatment of exacerbated migraine, recurrence of symptoms is a frequent issue. Therefore, patients have to be educated and equipped with adequate outpatient treatment options. So far no regimen successfully preventing relapse has been reported in pediatrics. In adults the use of steroids for aborting refractory migraine as well as for preventing recurrence is currently discussed. For the treatment of exacerbated TTH no pediatric data are available. Parenteral analgesics, particularly acetylsalicylic acid (if not contraindicated), seem to be the most reasonable choice.

\section{Prophylaxis}

Up to one-third of pediatric migraineurs meet the criteria for pharmacologic prophylaxis, and several patients prone to frequent TTH or CTTH may benefit from pharmacologic prophylaxis. ${ }^{16,23}$ Antidepressants, antihypertensives, antihistamines, and antiepileptics are commonly prescribed options. However, for most of these regimens evidence is still limited and effective dose levels are rarely established. ${ }^{19,24,54}$ Thus, when choosing an individual preventive strategy the available evidence, extrapolated adult data, and clinical expertise should be taken into account. ${ }^{20,21}$ Currently, novel data concerning amitriptyline, propranolol, calciumchannel blockers, topiramate (TPM), and VPA are available, as well as for melatonin and the new botulinum toxin strategy (-Table 8). Agents not studied since 2008 are displayed in -Table 5, drugs potentially beneficial for pediatric patients but only evaluated in adults so far are listed in - Table $\mathbf{6}$.

\section{Antidepressants}

Amitriptyline. Amitriptyline is a second-line option in the prevention of adult migraine. ${ }^{38}$ GNG 2008 equally classified amitriptyline $(1 \mathrm{mg} / \mathrm{kg})$ as a drug of second choice in adolescents and in individual cases even for younger children. ${ }^{14}$ An open-label trial and a retrospective analysis confirmed the efficacy of amitriptyline even in lower doses ( 0.5 and 0.2 to 0.4 $\mathrm{mg} / \mathrm{kg}$, respectively). ${ }^{55}$ In the retrospective study, the responder rate was as good as under propranolol, but significantly more (tolerable) side effects were reported in the amitriptyline group. ${ }^{56}$ In clinical routine amitriptyline is generally well accepted by the patients, because only one dose of the retard release formulation (not the slow release formulation) is necessary and taken in the evening the side effect of "mild sedation" is rarely an issue. A conservative approach targets a dose of 1 to $2 \mathrm{mg} / \mathrm{kg}$, but a lower dose (0.2-0.4 mg/kg) may also be sufficient. Due to the risk of arrhythmia an electrocardiogram should be obtained before prescription and if patients report cardiac side effects during therapy. Regarding the prevention of pediatric CTTH, two former small cohort openlabel trials reported efficacy of amitriptyline $(1 \mathrm{mg} / \mathrm{kg}$ and $10 \mathrm{mg}$, respectively). ${ }^{14}$ In adult CTTH amitriptyline is one of the first-line agents. ${ }^{46,57}$
In 2008, a consensus statement recommended amitriptyline as the first-line preventative in patients $\geq 5$ years prone to CVS based on open-label trials and recall surveys reporting up to $72 \%$ responder rates. ${ }^{58}$ A subsequent recall survey confirmed the good efficacy profile but revealed a relevant proportion of side effects. Nevertheless, the overall profile of amitriptyline was reported to be satisfactory in CVS. ${ }^{59}$

\section{Antihypertensives}

Propranolol. GNG 2008 graded the $\beta$-blocker propranolol $(2 \mathrm{mg} / \mathrm{kg}$ ) as a first-line option for the prophylaxis of pediatric migraine, similar to adults. ${ }^{14,38}$ As propranolol is frequently used as a comparative agent in controlled trials for migraine prevention in pediatrics, novel data from four trials are available. All four demonstrated efficacy and safety parameters in line with previous studies, even in lower doses $(0.5$ to $1 \mathrm{mg}$ / $\mathrm{kg})^{55,56,60,61}$ Propranolol must not be prescribed to patients with a history of atopic disease, asthma, diabetes, or heart block. Moreover, the authors do not administer propranolol to athletic patients because it may interfere with their physical activity.

Flunarizine. Flunarizine (5 to $10 \mathrm{mg}$ ), a nonselective calcium channel blocker with selective effects on the cerebrovascular circulation, is one of the first-line agent in adult migraine prevention. ${ }^{38}$ Similarly, it was rated as a first-line choice for pediatric migraineurs in $2008 .{ }^{14} \mathrm{~A}$ recent retrospective analysis reported responder rates and tolerability parameters in line with previous findings, as did one openlabel trial. ${ }^{55}$ Remarkably, efficacy was particularly high in patients suffering hemiplegic migraine. ${ }^{62}$ Because of the long half-life of flunarizine once-daily dosing is sufficient. As sedation is a commonly observed side effect, bedtime dosing is advisable. Flunarizine-associated weight gain can limit its prescription.

Cinnarizine. The L-type calcium channel blocker cinnarizine was shown to be effective and safe for prophylaxis in adult migraineurs. ${ }^{46}$ One recent randomized open-label trial demonstrated an efficacy and safety profile similar to propranolol in pediatric migraineurs. ${ }^{60}$

\section{Antihistamines}

Cyproheptadine. Cyproheptadine, an antihistamine additionally exerting antiserotonergic properties, was recently considered to be possibly effective in the prevention of adult migraine by the American Academy of Neurology. ${ }^{63}$ In pediatrics, it has been prescribed since the $1980 s^{53}$ However, efficacy data are limited to one former retrospective study and one small cohort open-label trial in migraineurs younger than 12 years. Both studies reported cyproheptadine to be effective. ${ }^{19,55}$ Despite the lack of data, cyproheptadine ( 0.2 to $0.4 \mathrm{mg} / \mathrm{kg}$ ) is regarded as the first-line option in young children ( $<6$ years) and children unable to swallow tablets in several current reviews. Relevant side effects are sedation and weight gain due to increased appetite. ${ }^{20,21}$

\section{Antiepileptics}

Valproate. VPA is an established first-line option in the prevention of adult migraine. ${ }^{38}$ GNG 2008 recommended VPA (20 to $30 \mathrm{mg} / \mathrm{kg}$ ) as a third-line option emphasizing the 
14 Pharmacotherapy of Pediatric Migraine and TTH Bonfert et al.

Table 8 Prophylactic drugs for the prevention of pediatric primary headaches addressed in clinical reports since 2008

\begin{tabular}{|c|c|c|c|}
\hline $\begin{array}{l}\text { Reference } \\
\text { Indication }\end{array}$ & Drug (dosage) & $\begin{array}{l}\text { Study design, number of patients (N), } \\
\text { age of patients, and study period (SP) }\end{array}$ & Results \\
\hline $\mathrm{M}^{55}$ & $\begin{array}{l}\text { AMT }(0.5 \mathrm{mg} / \mathrm{kg}) \\
\text { CYP }(0.2 \mathrm{mg} / \mathrm{kg}) \\
\text { FLU }(5-10 \mathrm{mg}) \\
\text { PRO }(10-40 \mathrm{mg})\end{array}$ & $\begin{array}{l}\text { OL; AMT } N=21, \text { CYP } N=17 \text {, FLU } N=19 \\
\text { PRO } N=20 ; 12.98 \pm 3.11 \text { yr; SP: } 16 \text { wk }\end{array}$ & $\begin{array}{l}\text { Significant RMHF, RHI, RDHE, and PedMIDAS score }(p<0.05) \text { in all } \\
\text { groups; CYP was more effective in reducing headache duration and HI } \\
\text { than the other agents }(p<0.05) \text {; AMT was more effective in reducing } \\
\text { MHF than the other agents }(p<0.05) \text {; AE: no data reported }\end{array}$ \\
\hline $\mathrm{M}^{56}$ & $\begin{array}{l}\text { AMT }(0.2-0.4 \mathrm{mg} / \mathrm{kg}) \\
\text { PRO }(0.5-1 \mathrm{mg} / \mathrm{kg})\end{array}$ & $\begin{array}{l}\text { RCR and follow-up interview; } N=25 \text { first-line } \\
\text { AMT, } N=20 \text { second-line AMT, } N=93 \text { PRO; } \\
4-18 \text { yr; SP: AMT } 26 \pm 15 \text { mo, PRO } 22 \pm 17\end{array}$ & $\begin{array}{l}\text { RBHF } \geq 50 \% \text { : AMT } 82.2 \%, \text { propranolol } 85 \% \text { of patients (N.S.); } \\
\text { AE: significant more common on AMT versus propranolol }(p<0.05) \text {; } \\
\text { AMT } N=9 \text { (weight gain, fainting, drowsiness, tremor); PRO (no } \\
\text { hypotonia, no bradycardia, no other data reported); no dropout }\end{array}$ \\
\hline $\operatorname{CVS}^{59}$ & AMT (not specified) & $\begin{array}{l}\text { Recall survey; } N=249 \text {; age not specified; } \\
\text { SP: not specified }\end{array}$ & $\begin{array}{l}\text { Relevant reduction in at least one of the outcome parameters } \\
\text { (frequency, duration, number of emesis, severity of nausea) in } 72 \% \text { of } \\
\text { patients; satisfaction with drug: } 47 \% \text { of patients, } 62 \% \text { of patients } \\
\text { would recommend it to other patients; AE: } 50 \% \text { of patients (not } \\
\text { specified); dropout of } 21 \% \text { of patients }\end{array}$ \\
\hline $\mathrm{M}^{62}$ & FLU (2.5-10 mg) & $\begin{array}{l}\text { RCR and follow-up interview; } N=72 \text {; } \\
1-17 \text { yr; SP: } 12 \text { mo }\end{array}$ & $\begin{array}{l}\text { RBHF } \geq 50 \%: 57 \% \text { of all patients; } 85 \% \text { of hemiplegic migraine } \\
\text { patients; AE: } 21 \% \text { of patients (depression, weight gain, sedation, } \\
\text { worse headache); dropout of } 18 \% \text { of patients }\end{array}$ \\
\hline $\mathrm{M}^{60}$ & $\begin{array}{l}\text { CIN }(37.5 ; 50 \mathrm{mg}) \\
\text { PRO }(1 \mathrm{mg} / \mathrm{kg})\end{array}$ & $\begin{array}{l}\text { ROL; } N=120(\mathrm{R}), N=113(\mathrm{ITT}) ; 6-17 \mathrm{yr} \\
\mathrm{SP}: 12 \mathrm{wk}\end{array}$ & $\begin{array}{l}\text { RBHF } \geq 50 \% \text { : CIN 75\%, PRO } 72,5 \% \text { of patients (N.S.); RMHF: } \\
\text { significant in CIN and PRO ( } p<0.001) ; \mathrm{CIN} \text { versus PRO N.S.; sec- } \\
\text { ondary end points: significant RHI and RDHE in CIN and PRO (not } \\
\text { specified); AE: CIN } N=5 \text { (daytime sedation, irritability); PRO N=3 } \\
\text { (palpitation); no dropout }\end{array}$ \\
\hline $\mathrm{M}^{61}$ & $\begin{array}{l}\text { sVPA }(15-30 \mathrm{mg} / \mathrm{kg}) \\
\text { PRO }(2-3 \mathrm{mg} / \mathrm{kg})\end{array}$ & $\begin{array}{l}\text { RDB; } N=63(\mathrm{R}), N=60(\mathrm{ITT}) ; 5-15 \mathrm{yr} \\
\text { SP: } 16 \text { wk }\end{array}$ & $\begin{array}{l}\text { RBHF } \geq 50 \% \text { : VPA } 63 \%, \text { PRO } 83 \% \text { of patients (N.S.); RMHF: significant } \\
\text { in VPA and PRO }(p<0.05) \text {; MHF after treatment: significantly lower } \\
\text { in PRO versus VPA }(p<0.01) \text {; RHDW: significant in VPA and PRO } \\
(p<0.001) ; \text { AE: VPA } N=11 \text { (abdominal pain, drowsiness, weight } \\
\text { gain), PRO } N=3 \text { (vertigo, insomnia); no dropout }\end{array}$ \\
\hline $\mathrm{M}^{65}$ & sDVPA $(1,000 \mathrm{mg})$ & $\mathrm{OL} ; N=112 ; 12-18 \mathrm{yr} ; \mathrm{SP}: 12 \mathrm{mo}$ & $\begin{array}{l}\text { Adherence } \geq 6 \text { mo: } 74 \% ; \geq 12 \text { mo: } 47 \% \text {; reason of dropout: AE } 13 \% \text {, } \\
\text { lacking efficacy } 10 \% \text {, lost } 10.9 \% \text {; compliance } \geq 70 \%: 68 \% \text {; efficacy: } \\
\text { sustained RMHF of } 50 \% \text { over SP; AE: weight gain, nausea, somno- } \\
\text { lence, upper respiratory tract infection, increased ammonia, sinusitis } \\
\text { reported in } \geq 10 \% \text { of patients; SAE: } N=5,1 \text { possibly related } \\
\text { (hyperammonemia), } 1 \text { probably not related (peptic ulcer) }\end{array}$ \\
\hline $\mathrm{M}^{64}$ & sDVPA (250-1,000 mg) & $\begin{array}{l}\mathrm{OL} ; N=241, N=236(\mathrm{ITT}) ; 12-18 \mathrm{yr} \\
\mathrm{SP}: 12 \text { mo }\end{array}$ & $\begin{array}{l}\text { Adherence } \geq 6 \text { mo: } 64 \% \text {; } \geq 12 \text { mo: } 40 \% \text {; reason of dropout: AE } 17 \% \text {, } \\
\text { lost } 13 \% \text {; withdrawn consent } 12 \% \text {, noncompliance } 10 \% \text {; } \\
\text { compliance } \geq 70 \%: 54 \% \text {; efficacy: RMHF of } 75 \% \text { between } 1 \text { st and } 4 \text { th } \\
\text { month, sustained effect over SP; AE: nausea, vomiting, weight gain, } \\
\text { nasopharyngitis, migraine, upper respiratory tract infection reported } \\
\text { in } \geq 10 \% \text { of patients; SAE: } N=10,3 \text { probably not related (depression, } \\
\text { impulse-control disorder) }\end{array}$ \\
\hline$M^{66}$ & $\begin{array}{l}\text { sVPA }(15 \mathrm{mg} / \mathrm{kg}) \\
\text { TPM }(2 \mathrm{mg} / \mathrm{kg})\end{array}$ & $\begin{array}{l}\text { RCR; VPA } N=20 ; 11 \pm 1.65 \text { yr, TPM } N=28 \\
10.35 \pm 2.03 \text { yr; SP: not specified }\end{array}$ & $\begin{array}{l}\text { RMHF: significant in VPA, TPM; RHI: significant in VPA, TPM; RDHE: } \\
\text { significant in VPA, TPM; PedMIDAS: significant in VPA, TPM (all } \\
\text { parameters } p<0.05 \text { or } 0.01 \text { ); AE: VPA } N=2 \text { (raised liver } \\
\text { transaminases, drowsiness); TPM } N=4 \text { (nausea, mood change, } \\
\text { weight loss, weakness); no dropout }\end{array}$ \\
\hline $\operatorname{cVs}^{67}$ & VPA (10-40 mg/kg) & $\mathrm{OL} ; N=13 ; 3-10 \mathrm{yr} ; \mathrm{SP}: 2 \mathrm{wk}$ to $8 \mathrm{yr}$ & $\begin{array}{l}\text { Relevant reduction of frequency in } 85 \% \text { of patients; complete } \\
\text { resolution } N=2 \text {; marked improvement } N=9 \text {; treatment failure } \\
N=2 ; \mathrm{AE}: \text { none }\end{array}$ \\
\hline $\mathrm{CDH}^{68}$ & VPA $(1,000 \mathrm{mg})$ & $\begin{array}{l}\text { RDBPC; } N=70(\mathrm{CM} N=29 ; \mathrm{CTTH} N=41) \\
14-76 \text { yr; SP: } 12 \mathrm{wk}\end{array}$ & $\begin{array}{l}\text { CM: significant reduction in general pain level ( } p<0.05) \text {, maximum } \\
\text { pain level and pain frequency }(p<0.01) \text {; CTTH: significant reduction } \\
\text { in pain frequency }(p<0.001) \text {; AE: VPA } N=3 \text { (somnolence, tremor, } \\
\text { impotence, hair loss) } 3 \text { dropouts; placebo } N=1 \text { (dizziness, nausea), } \\
1 \text { dropout }\end{array}$ \\
\hline $\mathrm{M}^{69}$ & TPM (50-200 mg) & $\mathrm{RCR} ; N=37 ; 7-20 \mathrm{yr} ; \mathrm{SP}: 12 \pm 5 \mathrm{mo}$ & $\begin{array}{l}\text { RBHF } \geq 50 \%: 76 \% \text { of patients; RMHF: significant }(p<0.001) ; \\
\text { AE: } N=10 \text { (cognitive decline, drowsiness, paresthesia, anhidrosis), } \\
10 \text { dropouts } 7 \text { AE (cognitive issues, paresthesia, anhidrosis); } 3 \text { lack of } \\
\text { efficacy }\end{array}$ \\
\hline $\mathrm{M}^{70}$ & TPM (50 mg; 100 mg) & $\begin{array}{l}\text { RDBPC; } N=106(\mathrm{R}), N=103(\mathrm{ITT}) ; 12-17 \mathrm{yr} ; \\
\mathrm{SP}: 16 \mathrm{wk}\end{array}$ & $\begin{array}{l}\text { RMHF: TPM } 100 \text { versus placebo significant ( } p<0.05 \text { ); TPM } 50 \text { versus } \\
\text { placebo not significant; RBHF } \geq 50 \% \text { : TPM } 10083 \% \text {, placebo } 45 \% \\
\text { ( } p<0.01 \text { ); TPM } 50 \text { versus placebo not significant; AE: TPM } 74 \% \text {, } \\
\text { placebo } 48 \% \text { of patients; more common in TPM: upper respiratory } \\
\text { tract infection, paresthesia, anorexia; } 6 \text { dropouts (TPM } 100 \mathrm{~N}=2 \\
\text { (fatigue, renal calculus); TPM } 50 \mathrm{~N}=3 \text { (fatigue, nervousness, } \\
\text { headache/emotional lability/depression) placebo } N=1 \\
\text { (hypokalemia) }\end{array}$ \\
\hline $\mathrm{M} ; \mathrm{CTTH}^{71}$ & Melatonin (3 mg) & $\begin{array}{l}\text { OL; } N=22 \text { (migraine } N=14, \text { CTTH } N=8 \text { ); } \\
6-16 \text { yr; SP: } 12 \mathrm{wk}\end{array}$ & $\begin{array}{l}\text { RBHF } \geq 50 \%: 14 / 21 \text { patients (migraine } N=10, \mathrm{CTTH} N=4 \text { ) } \\
\mathrm{AE}: N=1 \text { (excessive daytime sleepiness), dropout of } 1 \text { patient }\end{array}$ \\
\hline $\mathrm{CM}^{73}$ & OnA (75-200 units) & $\begin{array}{l}\text { RCR; } N=45 ; 16.8 \pm 2.0 \mathrm{yr} \text { SP: interval } 2 \mathrm{mo} \\
\text { evaluation before second and third } \\
\text { intervention }\end{array}$ & $\begin{array}{l}\text { RMHF: significant ( } p<0.01 \text { ); RHI: no change; change from severe to } \\
\text { moderate disability in PedMIDAS (N.S.); AE: } N=8 \text { (pain at injection } \\
\text { site, eyelid infection, eyelid pain, swelling of left eyebrow, neck/ } \\
\text { shoulder myalgia); no dropout }\end{array}$ \\
\hline
\end{tabular}


Table 8 (Continued)

\begin{tabular}{|c|c|c|c|}
\hline $\begin{array}{l}\text { Reference } \\
\text { Indication }\end{array}$ & Drug (dosage) & $\begin{array}{l}\text { Study design, number of patients }(N) \text {, } \\
\text { age of patients, and study period (SP) }\end{array}$ & Results \\
\hline $\mathrm{CDH}^{72}$ & OnA (100 units) & $\begin{array}{l}\text { RCR; } N=10(C M N=5, \text { new onset } D H N=2, \\
C T T N=2 \text {, trochlear neuralgia } N=1) ; \\
11-17 \text { yr; SP: } 1-3 \text { injections, interval } 3 \text { mo }\end{array}$ & $\begin{array}{l}\text { Headache relief of clinical importance: } 4 / 10(\mathrm{CM} \mathrm{N}=3 / 5) ; \mathrm{AE}: \\
N=3 \text { (flulike symptoms, brachial paresthesia), no dropout }\end{array}$ \\
\hline $\mathrm{CDH}^{74}$ & OnA (100 units) & $\begin{array}{l}\text { RCR; } N=12 \text { (long-term treatment [LTT] } \\
N=6 ; \mathrm{CM} N=2 ; \mathrm{CDH}+\mathrm{M} \mathrm{N}=4 \text { ); } \\
14-18 \mathrm{yr} ; \mathrm{SP}: 3-29 \mathrm{mo} \text {, interval } 3 \mathrm{mo}\end{array}$ & $\begin{array}{l}\text { RHI: } 6 / 6 \text { LTT, complete relief } 2 / 6 \text {; improvement of quality of life: } 6 / 6 \\
\text { LTT; good response after first injection, further data missing: } N=4 \text {; } \\
\text { no improvement after first injection, treatment not continued: } \\
N=2 ; \text { AE: } N=4 \text { (ptosis, blurred vision, hematoma at injection site } \\
\text { with tingling in one arm, burning sensation at injection site) }\end{array}$ \\
\hline $\mathrm{CDH}^{75}$ & OnA (20-90 units) & $\begin{array}{l}\text { RCR and follow-up interview after } 10 \mathrm{yr} ; \\
N=5 \text { ( } N=1 \text { lost to follow-up); } 10-16 \mathrm{yr} ; \\
\text { SP: } 1-4 \text { injections, mean interval } 2.7 \text { mo }\end{array}$ & $\begin{array}{l}\text { Short-term effect: relevant } \mathrm{RMHF} \text { and } \mathrm{RHI} \text { in } 5 / 5 \text { patients; long-term: } \\
0 / 4 \text { patients reported } \mathrm{CDH} ; 4 / 4 \text { patients rated the intervention as } \\
\text { pivotal, decisive or helpful; } \mathrm{AE} \text { : none }\end{array}$ \\
\hline
\end{tabular}

Abbreviations: AMT, amitriptyline; $\mathrm{CDH}$, chronic daily headache; $\mathrm{CIN}$, cinnarizine; $\mathrm{CM}$, chronic migraine; CTTH, chronic tension-type headache; CVS, cyclic vomiting syndrome; CYP, cyproheptadine; FLU, flunarizine; ITT, intention to treat; kg, kilogram body weight; M, migraine; N.S., nonsignificant; OL, open-label trial; OnA, onabotulinumtoxin A; PedMIDAS, pediatric migraine disability score; PRO, propranolol; R, randomized; RBHF, reduction in baseline headache frequency; RCR, retrospective chart review; RDB, randomized, double-blind trial; RDBPC, randomized, double-blind, placebocontrolled trial; RHDW, reduction in headache duration per week; (R)DHE, (reduction in) duration of headache episode; (R)HI, (reduction in) headache intensity; (R)MHF, (reduction in) monthly headache frequency; s(D)VPA, sodium (di)valproate; (S)AE, (serious) adverse event; TPM, topiramate.

importance of respecting the contraindications, as pediatric data have been inconclusive. ${ }^{14}$ Since 2008 , four trials addressing pediatric migraine prevention with VPA have been published. In a randomized, double-blind trial VPA was rated as effective and safe as propranolol, but the primary outcome measure (reduction in baseline headache frequency $>50 \%$ ) favored propranolol. ${ }^{61}$ Sustained long-term efficacy up to 12 months was demonstrated in two open-label trials. ${ }^{64,65}$ Interestingly, reduction in headache frequency was reported to be relevant only from the 4 th month of treatment. Finally, one retrospective study reported effectiveness of VPA in reducing frequency, intensity, and duration of attacks as well as in overall disability. ${ }^{66}$ Tolerability profiles reported were similar to the data of previous trials and overall rated as "good." However, in the long-term studies increased ammonia levels were commonly observed, peaking $\geq 90 \mu \mathrm{mol} / \mathrm{L}$ in about $20 \%$ of subjects at least once during the study period. In most cases hyperammonemia was only transient, but these findings emphasize the importance of thorough surveillance and education about symptoms of hyperammonemia of patients on long-term VPA. ${ }^{64,65}$ Moreover, VPA contraindications need to be excluded before the start of treatment, and the risk of teratogenicity and fertility-related side effects have to be discussed with teenage patients. As the adverse effects seem to be dose dependent, a target dose of 15 to $20 \mathrm{mg} / \mathrm{kg}$ is reasonable. ${ }^{20}$ VPA has also been evaluated in the prevention of severe CVS with promising results regarding efficacy, even in previously treatment-resistant cases. ${ }^{67}$ Regarding chronic daily headache, one randomized, double-blind trial addressing mainly adult patients showed efficacy of VPA in chronic migraine and CTTH patients aged 14 years and above. ${ }^{68}$ VPA is a second-line option for the prevention of adult CTTH. ${ }^{57}$

Topiramate. TPM is among the first-line options for prevention of adult migraine. ${ }^{38} \mathrm{GNG} 2008$ rated TPM ( 1 to $3 \mathrm{mg} / \mathrm{kg}$ ) as effective but only a second-line choice due to the side effect profile. ${ }^{14}$ Since then, two retrospective studies showed the efficacy of TPM. ${ }^{66,69}$ Furthermore, one randomized, doubleblind trial confirmed the superiority of TPM $100 \mathrm{mg}$ over placebo. TPM $50 \mathrm{mg}$ failed to demonstrate superiority. ${ }^{70}$ All reports rated TPM as safe and well tolerated. In the report of Cruz et al, side effects were mainly correlated to TPM doses over $2 \mathrm{mg} / \mathrm{kg}$; thus, a target dose of 1 to $2 \mathrm{mg} / \mathrm{kg}$ (maximum $100 \mathrm{mg}$ ) could be reasonable. ${ }^{69}$ Overall, particularly overweight patients and patients with epilepsy may benefit from TPM. In prevention of CTTH pediatric data concerning TPM are limited to one former small recall survey that reported TPM (15 to $100 \mathrm{mg}$ ) to be effective. ${ }^{14}$ In adult CTTH, TPM is an agent of further choice. ${ }^{46,57}$

\section{Others}

Melatonin. Limited evidence for the effectiveness of melatonin in the prevention of adult headache exists. ${ }^{46}$ One small trial reported efficacy in pediatric migraine and CTTH patients. $^{71}$

Onabotulinumtoxin A (OnA). OnA was approved for the prevention of adult chronic migraine in 2010 by the FDA and in 2011 by European authorities. Pediatric data are limited to three retrospective studies and one retrospective case series with long-term follow-up showing promising effects and a good tolerability profile in several patients suffering chronic primary headache. ${ }^{72-75}$

\section{Authors' Comments on Prophylaxis}

In general, the authors propagate a defensive much more than an offensive strategy regarding pharmacoprophylaxis. First, nonpharmacologic measures should be established. These include lifestyle modification, regular exercise, stress relaxation, biobehavioral and psychotherapeutic intervention, and complementary measures. In general, pharmacologic prophylaxis is only indicated if those actions have been ineffective or insufficient. In the authors' opinion, some patients may benefit from a multimodal regimen in the beginning, in particular the severely disabled or those at risk for chronic disease. For example, pharmacologic prevention may bridge time until a consistent response to behavioral therapy is achieved. ${ }^{16}$ For the prevention of pediatric migraine, flunarizine, propranolol, and amitriptyline are established options. Flunarizine is particularly beneficial in patients prone to hemiplegic migraine. TPM is widely used, but tolerability, side effect profile, and 
contraindications have to be discussed. Acetylsalicylic acid can be an alternative in adolescents, although increased risk of bleeding may be a relative contraindication. The use of cyproheptadine is often cited in younger children, but due to limited evidence and lack of our own experience the authors cannot recommend it. VPA does not seem to be a reasonable choice for the long-term treatment due to its side effect profile. The value of cinnarizine and melatonin as well as zonisamide in the prophylaxis of pediatric migraine should be further evaluated in controlled trials. For gapapentin pediatric data are missing. Botulinum toxin remains an experimental option in the younger population. Injection regimens have to be adapted and controlled studies have to be launched. Despite these restrictions, botulinum toxin can be regarded as a reserve option in severely disabled patients with chronic primary headache who experience treatment resistance to other (at least two) agents, including multimodality. If and to what extent the so-called (active) muscular trigger points are a sufficient and guiding concept for this new treatment option when transferred to adolescents and even children is speculative. ${ }^{13,75}$ All other agents have fairly been systematically investigated regarding prevention of pediatric chronic migraine, CTTH, and chronic daily headache so far. Hence, the use of the above-mentioned preventatives, particularly amitriptyline and TPM, should be taken into consideration. For the use of mirtazapine and tizanidine in pediatric CTTH, no data are currently available. Patients suffering CVS could benefit from amitriptyline or, assuming a thorough risk-to-benefit analysis, VPA.

\section{Discussion}

Primary headaches are a common health issue in children and adolescents. ${ }^{7,13}$ Adequate therapy undoubtedly must be guaranteed, not only to improve the current health status of the patients but also to prevent progress to chronic disease in adulthood. ${ }^{26}$ High-quality evidence for the pharmacologic treatment of pediatric primary headaches is still fairly limited, but advances can be reported, particularly regarding the symptomatic treatment of migraine with triptans. However, today only a minority of pediatric migraineurs receives migraine-specific outpatient treatment. ${ }^{76}$ With the new data available and the coherent approval modifications by the FDA and EMA taken into account, the use of triptans should no longer be generally denied to children and adolescents. Agents as effective and safe as triptans should be available to both adult AND pediatric patients. Migraine-specific agents such as triptans may have advantages in the long run that are not yet known compared with unspecific drugs such as analgesics (i.e., long-term outcome or modification of condition). Another issue is the emergent treatment of exacerbated migraine. Some pediatricians tend to hesitate or refuse to use currently available potentially effective agents. $^{51}$ In this context, an Australian audit reported emergent treatment to be markedly delayed (median, 2 hours) even though the average interval between onset of migraine and visit to the ED was $\geq 2$ days. ${ }^{42}$ Moreover, despite treatment resistance experienced with their recommended outpatient regimen, only about $60 \%$ of ED patients receive a treatment in line with the limited available evidence (dopamine antagonists, analgesics, NSAIDs, triptans, DHE) and only a few patients receive migraine-specific agents (triptans, 0.5 to $1 \%$; DHE, $0.9 \%$ ) at all. ${ }^{42,43}$ Because early aggressive treatment is the key to preventing disability and allodynia, these numbers are not acceptable. Patients suffering exacerbated migraine should be treated in a satisfying manner by applying existing options. Concerning preventive pharmacologic therapy of migraine, about onethird of adolescents meet the criteria, although only 10 to $19 \%$ are offered prophylaxis. ${ }^{16,22}$ Efforts to make effective prophylactics available to all patients are evidently necessary. Also, novel prevention options with reasonable safety profiles must not be generally denied to children and adolescents, because they may imply an important benefit in the long term, taking into account the putative mechanisms of action.

Even with the progress of the last years, appropriate treatment of primary headaches still remains an unmet medical need in pediatric medicine. Several factors contribute to the paucity of reliable data for migraine. First, in pediatric trials, an age-dependent high placebo response rate is an issue, to some extent attributed to the generally shorter duration of acute attacks. ${ }^{18,27}$ Depending on the study design, the placebo rate can be $69 \%$ in acute and $55 \%$ in preventive treatment, respectively. ${ }^{18,19,21}$ Therefore, the proof of superiority over placebo is difficult to supply and requires a complex study design and adequately powered trials. Second, the classification of pediatric patients in the line with IHS criteria may not always be appropriate. Pediatric study populations may tend to be more heterogeneous due to the high prevalence of mixed-type headache. Third, study periods, end points and assessment instruments may not be equally suitable for all age groups with respect to the natural evolution of the condition. ${ }^{21,27,54}$ Most of these factors could also be transferred to the issue of pediatric TTH trials, a field even less investigated. In this context, another issue in pediatric headaches should be mentioned. The IHS classification is barely suitable for numerous pediatric patients from the clinical point of view because the frequent mixed-type headache is not sufficiently addressed. In those patients, individually tailored treatment strategies should focus on the most current complaints.

All the above-named factors should be considered in future pediatric headache research. Issues to be principally addressed include the following:

- Controlled (head-to-head) comparison of efficacy and safety profiles of different drugs and their formulations, respectively

- Detailed investigation of the complex properties of several agents in migraine (e.g., triptans, dopamine antagonists)

- Long-term efficacy and safety profiles of agents, including the transition period to adulthood

- Effective strategies to prevent relapse after successful treatment of acute exacerbated migraine 
- Controlled studies assessing multimodality (including pharmacotherapy) as the proclaimed treatment option

\section{Conclusion}

Pharmacotherapy of primary headaches is a medical field appropriate for practicing personalized medicine. A variety of agents is available, and the team of patient, parents, and physician (and psychologist) needs to decide on the best treatment strategy by taking into account the different properties of available drugs. Drug profiles are complex and demand a well-considered and thorough handling. However, they allow the same full range of individualization in children and adolescents as in adults. Because profiles of many agents differ only slightly or even overlap, a hierarchical grading of their use seems inappropriate, particularly considering the limited pediatric evidence available to most of them. As often in pediatric pharmacotherapy, off-label use of drugs is the norm in almost all settings of headache treatment. In addition to over-thecounter analgesics, only four triptans for acute migraine and flupirtine for acute TTH have been approved by different regulatory authorities. For the prevention of pediatric primary headache no agent has been approved so far. Thus, the treatment of pediatric primary headaches remains an unmet medical need, and further research is definitely necessary.

\section{References}

1 World Health Organization, Lifting the Burden. Atlas of Headache Disorders and Resources in the World 2011. A Collaborative Project of World Health Organization and Lifting The Burden. Geneva: World Health Organization; 2011

2 Berg Kelly K, Ehrvér M, Erneholm T, Gundevall C, Wennerberg I, Wettergren L. Self-reported health status and use of medical care by 3,500 adolescents in western Sweden. I. Acta Paediatr Scand 1991;80(8-9):837-843

3 Roth-Isigkeit A, Thyen U, Raspe HH, Stöven H, Schmucker P. Reports of pain among German children and adolescents: an epidemiological study. Acta Paediatr 2004;93(2):258-263

4 Ellert U, Neuhauser H, Roth-Isigkeit A. [Pain in children and adolescents in Germany: the prevalence and usage of medical services. Results of the German Health Interview and Examination Survey for Children and Adolescents (KiGGS)]. Bundesgesundheitsblatt Gesundheitsforschung Gesundheitsschutz 2007; 50(5-6):711-717

5 Hershey AD. Pediatric headache: update on recent research. Headache 2012;52(2):327-332

6 Larsson B, Fichtel A. Headache prevalence and characteristics among school children as assessed by prospective paper diary recordings. J Headache Pain 2012;13(2):129-136

7 Milde-Busch A, Blaschek A, Borggräfe I, von Kries R, Straube A, Heinen $F$. [Is there an association between the reduced school years in grammar schools and headache and other health complaints in adolescent students?] Klin Padiatr 2010;222(4):255-260

8 Abu-Arafeh I, Razak S, Sivaraman B, Graham C. Prevalence of headache and migraine in children and adolescents: a systematic review of population-based studies. Dev Med Child Neurol 2010;52(12):1088-1097

9 The International Classification of Headache Disorders. 2nd edition. Cephalalgia 2004;24(Suppl 1):9-160

10 Rho YI, Chung HJ, Lee KH, et al. Prevalence and clinical characteristics of primary headaches among school children in South Korea: a nationwide survey. Headache 2012;52(4):592-599
11 Kröner-Herwig B, Heinrich M, Morris L. Headache in German children and adolescents: a population-based epidemiological study. Cephalalgia 2007;27(6):519-527

12 Fendrich K, Vennemann M, Pfaffenrath V, et al. Headache prevalence among adolescents-the German DMKG headache study. Cephalalgia 2007;27(4):347-354

13 Blaschek A, Milde-Busch A, Straube A, et al. Self-reported muscle pain in adolescents with migraine and tension-type headache. Cephalalgia 2012;32(3):241-249

14 Ebinger F, Kropp P, Pothmann R, Heinen F, Evers S. Therapie idiopathischer Kopfschmerzen im Kindes- und Jugendalter. Revidierte Empfehlungen der Gesellschaft für Neuropädiatrie (GNP) und der Deutschen Migräne- und Kopfschmerzgesellschaft (DMKG). Monatsschr Kinderheilkd 2009;157:599-610

15 Khan K, Kunz R, Kleijnen J, Antes G. Systematic Reviews to Support Evidence-Based Medicine: How to Review and Apply Findings of Healthcare Research. London, UK: Royal Society of Medicine, Hodder Education; 2011

16 Winner P. Pediatric headache. Curr Opin Neurol 2008;21(3): 316-322

17 Papetti L, Spalice A, Nicita F, et al. Migraine treatment in developmental age: guidelines update. J Headache Pain 2010;11(3): 267-276

18 Hershey AD. Current approaches to the diagnosis and management of paediatric migraine. Lancet Neurol 2010;9(2):190-204

19 Termine C, Ozge A, Antonaci F, Natriashvili S, Guidetti V, WöberBingöl C. Overview of diagnosis and management of paediatric headache. Part II: therapeutic management. J Headache Pain 2011;12(1):25-34

20 O'Brien HL, Kabbouche MA, Hershey AD. Treating pediatric migraine: an expert opinion. Expert Opin Pharmacother 2012;13 (7):959-966

21 Jacobs H, Gladstein J. Pediatric headache: a clinical review. Headache 2012;52(2):333-339

22 Cuvellier JC, Carvalho S, Mars A, Auvin S. Study on management of pediatric migraine by general practitioners in northern France. J Headache Pain 2009;10(3):167-175

23 Seshia SS, Abu-Arafeh I, Hershey AD. Tension-type headache in children: the Cinderella of headache disorders!. Can J Neurol Sci 2009;36(6):687-695

24 Parisi P, Papetti L, Spalice A, Nicita F, Ursitti F, Villa MP. Tension-type headache in paediatric age. Acta Paediatr 2011;100(4):491-495

25 Manzano S, Doyon-Trottier E, Bailey B. Myth: Ibuprofen is superior to acetaminophen for the treatment of benign headaches in children and adults. CJEM 2010;12(3):220-222

26 Mannix LK. A review of the 5-HT1B/1D agonist rizatriptan: update on recent research and implications for the future. Expert Opin Pharmacother 2008;9(6):1001-1011

27 Ho TW, Pearlman E, Lewis D, et al; Rizatriptan Protocol 082 Pediatric Migraine Study Group. Efficacy and tolerability of rizatriptan in pediatric migraineurs: results from a randomized, double-blind, placebo-controlled trial using a novel adaptive enrichment design. Cephalalgia 2012;32(10):750-765

28 Vollono C, Vigevano F, Tarantino S, Valeriani M. Triptans other than sumatriptan in child and adolescent migraine: literature review. Expert Rev Neurother 2011;11(3):395-401

29 Linder SL, Mathew NT, Cady RK, Finlayson G, Ishkanian G, Lewis DW. Efficacy and tolerability of almotriptan in adolescents: a randomized, double-blind, placebo-controlled trial. Headache 2008;48(9):1326-1336

30 Lewis DW. Almotriptan for the acute treatment of adolescent migraine. Expert Opin Pharmacother 2010;11(14):2431-2436

31 Fraser IP, Han L, Han TH, et al. Pharmacokinetics and tolerability of rizatriptan in pediatric migraineurs in a randomized study. Headache 2012;52(4):625-635

32 Kakisaka Y, Wakusawa K, Sato I, et al. Successful treatment with sumatriptan in a case with cyclic vomiting syndrome 
combined with 18q- syndrome. J Child Neurol 2009;24(12): 1561-1563

33 Kakisaka Y, Wakusawa K, Haginoya K, et al. Efficacy of sumatriptan in two pediatric cases with abdominal pain-related functional gastrointestinal disorders: does the mechanism overlap that of migraine? J Child Neurol 2010;25(2):234-237

34 Hikita T, Kodama H, Kaneko S, et al. Sumatriptan as a treatment for cyclic vomiting syndrome: a clinical trial. Cephalalgia 2011; 31(4):504-507

35 Cleves C, Tepper SJ. Sumatriptan/naproxen sodium combination for the treatment of migraine. Expert Rev Neurother 2008;8(9): 1289-1297

36 Derosier FJ, Lewis D, Hershey AD, et al. Randomized trial of sumatriptan and naproxen sodium combination in adolescent migraine. Pediatrics 2012;129(6):e1411-e1420

37 McDonald SA, Hershey AD, Pearlman E, et al. Long-term evaluation of sumatriptan and naproxen sodium for the acute treatment of migraine in adolescents. Headache 2011;51(9):1374-1387

38 Evers S, May A, Fritsche G, et al. Akuttherapie und Prophylaxe der Migräne. Leitlinie der Deutschen Migräne- und Kopfschmerzgesellschaft und der Deutschen Gesellschaft für Neurologie. Nervenheilkunde 2008;27:933-949

39 Scagni P, Pagliero R. Headache in an Italian pediatric emergency department. J Headache Pain 2008;9(2):83-87

40 Kabbouche MA, Vaughan P, Cherney S, Powers SE, Hershey AD. Intractable headache response in a pediatric acute care unit. Cephalalgia 2009;29:16-17

41 Conicella E, Raucci U, Vanacore N, et al. The child with headache in a pediatric emergency department. Headache 2008;48(7):1005-1011

42 Herd DW, Babl FE, Gilhotra Y, Huckson S; PREDICT group. Pain management practices in paediatric emergency departments in Australia and New Zealand: a clinical and organizational audit by National Health and Medical Research Council's National Institute of Clinical Studies and Paediatric Research in Emergency Departments International Collaborative. Emerg Med Australas 2009; 21(3):210-221

43 Richer LP, Laycock K, Millar K, et al; Pediatric Emergency Research Canada Emergency Department Migraine Group. Treatment of children with migraine in emergency departments: national practice variation study. Pediatrics 2010;126(1):e150-e155

44 Walker DM, Teach SJ. Emergency department treatment of primary headaches in children and adolescents. Curr Opin Pediatr 2008;20(3):248-254

45 Bailey B, McManus BC. Treatment of children with migraine in the emergency department: a qualitative systematic review. Pediatr Emerg Care 2008;24(5):321-330

46 Sarchielli P, Granella F, Prudenzano MP, et al. Italian guidelines for primary headaches: 2012 revised version. J Headache Pain 2012;13(Suppl 2):S31-S70

47 Legault G, Eisman H, Shevell MI. Treatment of pediatric status migrainosus: can we prevent the "bounce back"? J Child Neurol 2011;26(8):949-955

48 Trottier ED, Bailey B, Dauphin-Pierre S, Gravel J. Clinical outcomes of children treated with intravenous prochlorperazine for migraine in a pediatric emergency department. J Emerg Med 2010;39(2):166-173

49 Trottier ED, Bailey B, Lucas N, Lortie A. Prochlorperazine in children with migraine: a look at its effectiveness and rate of akathisia. Am J Emerg Med 2012;30(3):456-463

50 Khatri R, Hershey AD, Wong B. Prochlorperazine-treatment for acute confusional migraine. Headache 2009;49(3):477-480

51 Kabbouche MA, Powers SW, Segers A, et al. Inpatient treatment of status migraine with dihydroergotamine in children and adolescents. Headache 2009;49(1):106-109

52 Avraham SB, Har-Gil M, Watemberg N. Acute confusional migraine in an adolescent: response to intravenous valproate. Pediatrics 2010;125(4):e956-e959
53 Kabbouche MA, Gilman DK. Management of migraine in adolescents. Neuropsychiatr Dis Treat 2008;4(3):535-548

54 Mack KJ. Management of chronic daily headache in children. Expert Rev Neurother 2010;10(9):1479-1486

55 Hirfanoglu T, Serdaroglu A, Gulbahar O, Cansu A. Prophylactic drugs and cytokine and leptin levels in children with migraine. Pediatr Neurol 2009;41(4):281-287

56 Eidlitz-Markus T, Dlugatch Y, Haimi-Cohen Y, Goldberg-Stern H Zeharia A. Nonpharmacologic treatment of migraine with lowdose propranolol or amitriptyline. Pediatr Neurol 2012;46 (6):345-349

57 Straube A, May A, Kropp P, et al. Therapie primärer chronischer Kopfschmerzen: Chronische Migräne, chronischer Kopfschmerz vom Spannungstyp und andere chronische tägliche Kopfschmerzen. Evidenzbasierte Empfehlungen der Deutschen Migräne- und Kopfschmerzgesellschaft in Zusammenarbeit mit der Österreichischen Kopfschmerzgesellschaft und der Schweizerischen Kopfwehgesellschaft. Nervenheilkunde 2007;26:186-199

58 Li BU, Lefevre F, Chelimsky GG, et al; North American Society for Pediatric Gastroenterology, Hepatology, and Nutrition. North American Society for Pediatric Gastroenterology, Hepatology, and Nutrition consensus statement on the diagnosis and management of cyclic vomiting syndrome. J Pediatr Gastroenterol Nutr 2008;47(3):379-393

59 Boles RG, Lovett-Barr MR, Preston A, Li BU, Adams K. Treatment of cyclic vomiting syndrome with co-enzyme Q10 and amitriptyline, a retrospective study. BMC Neurol 2010;10:10

60 Togha M, Malamiri RA, Rashidi-Ranjbar N, Asa S, Mahvelati F, Ashrafi MR. Efficacy and safety of cinnarizine in the prophylaxis of migraine headaches in children: an open, randomized comparative trial with propranolol. Acta Neurol Belg 2012;112(1): 51-55

61 Bidabadi E, Mashouf M. A randomized trial of propranolol versus sodium valproate for the prophylaxis of migraine in pediatric patients. Paediatr Drugs 2010;12(4):269-275

62 Peer Mohamed B, Goadsby PJ, Prabhakar P. Safety and efficacy of flunarizine in childhood migraine: 11 years' experience, with emphasis on its effect in hemiplegic migraine. Dev Med Child Neurol 2012;54(3):274-277

63 Holland S, Silberstein SD, Freitag F, Dodick DW, Argoff C, Ashman E; Quality Standards Subcommittee of the American Academy of Neurology and the American Headache Society. Evidence-based guideline update: NSAIDs and other complementary treatments for episodic migraine prevention in adults: report of the Quality Standards Subcommittee of the American Academy of Neurology and the American Headache Society. Neurology 2012;78 (17):1346-1353

64 Apostol G, Lewis DW, Laforet GA, et al. Divalproex sodium extended-release for the prophylaxis of migraine headache in adolescents: results of a stand-alone, long-term open-label safety study. Headache 2009;49(1):45-53

65 Apostol G, Pakalnis A, Laforet GA, et al. Safety and tolerability of divalproex sodium extended-release in the prophylaxis of migraine headaches: results of an open-label extension trial in adolescents. Headache 2009;49(1):36-44

66 Unalp A, Uran N, Oztürk A. Comparison of the effectiveness of topiramate and sodium valproate in pediatric migraine. J Child Neurol 2008;23(12):1377-1381

67 Hikita T, Kodama H, Nakamoto N, et al. Effective prophylactic therapy for cyclic vomiting syndrome in children using valproate. Brain Dev 2009;31(6):411-413

68 Yurekli VA, Akhan G, Kutluhan S, Uzar E, Koyuncuoglu HR, Gultekin F. The effect of sodium valproate on chronic daily headache and its subgroups. J Headache Pain 2008;9(1):37-41

69 Cruz MJ, Valencia I, Legido A, et al. Efficacy and tolerability of topiramate in pediatric migraine. Pediatr Neurol 2009;41(3): $167-170$ 
70 Lewis D, Winner P, Saper J, et al. Randomized, double-blind, placebo-controlled study to evaluate the efficacy and safety of topiramate for migraine prevention in pediatric subjects 12 to 17 years of age. Pediatrics 2009;123(3):924-934

71 Miano S, Parisi P, Pelliccia A, Luchetti A, Paolino MC, Villa MP. Melatonin to prevent migraine or tension-type headache in children. Neurol Sci 2008;29(4):285-287

72 Ahmed K, Oas KH, Mack KJ, Garza I. Experience with botulinum toxin type $\mathrm{A}$ in medically intractable pediatric chronic daily headache. Pediatr Neurol 2010;43(5):316-319

73 Kabbouche M, O'Brien H, Hershey AD. OnabotulinumtoxinA in pediatric chronic daily headache. Curr Neurol Neurosci Rep 2012;12(2):114-117

74 Chan VW, McCabe EJ, MacGregor DL. Botox treatment for migraine and chronic daily headache in adolescents. J Neurosci Nurs 2009;41(5):235-243

75 Schroeder AS, Huss K, Blaschek A, et al. Ten-year follow-up in a case series of integrative botulinum toxin intervention in adoles- cents with chronic daily headache and associated muscle pain. Neuropediatrics 2012;43(1):27-36

76 Kernick D, Stapley S, Campbell J, Hamilton W. What happens to new-onset headache in children that present to primary care? A case-cohort study using electronic primary care records. Cephalalgia 2009;29(12):1311-1316

77 Haag G, Diener HC, May A, et al; DMKG; DGN; OKSG; SKG. Selfmedication of migraine and tension-type headache: summary of the evidence-based recommendations of the Deutsche Migräne und Kopfschmerzgesellschaft (DMKG), the Deutsche Gesellschaft für Neurologie (DGN), the Österreichische Kopfschmerzgesellschaft (ÖKSG) and the Schweizerische Kopfwehgesellschaft (SKG). J Headache Pain 2011;12(2):201-217

78 Shah UH, Kalra V. Pediatric migraine. Int J Pediatr 2009;7:424192

79 Schrör K. Aspirin and Reye syndrome: a review of the evidence. Paediatr Drugs 2007;9(3):195-204

80 Rapoport AM. The therapeutic future in headache. Neurol Sci 2012;33(Suppl 1):S119-S125 